\title{
ON AUTONOMY SUPPORT: LOW-INCOME MOTHERS' PARENTING OF YOUNG CHILDREN IN CONTEMPORARY CHINA AND THE U.S.
}

\begin{tabular}{|c|}
\hline A Dissertation \\
\hline Presented to \\
\hline the Faculty of the Graduate School \\
\hline at the University of Missouri-Columbia \\
\hline In Partial Fulfillment \\
\hline of the requirements for the Degree \\
\hline Doctor of Philosophy \\
\hline by \\
\hline CHANG SU-RUSSELL \\
\hline Dr. Jean Ispa, Dissertation Supervisor \& Academic Advisor \\
\hline May, 2018 \\
\hline
\end{tabular}


The undersigned, appointed by the dean of the Graduate School, have examined the dissertation entitled

\section{ON AUTONOMY SUPPORT: LOW-INCOME MOTHERS' PARENTING OF YOUNG CHILDREN IN CONTEMPORARY CHINA AND THE U.S.}

Presented by Chang Su-Russell

A candidate for the degree of doctor of philosophy,

And hereby certify that, in their opinion, it is worthy of acceptance

\begin{tabular}{c}
\hline Dr. Jean Ispa \\
\hline Dr. Gustavo Carlo \\
\hline Dr. Duane Rudy \\
\hline Dr. Candace Kuby
\end{tabular}




\section{ON AUTONOMY SUPPORT}

\section{Dedication}

I attribute my completion of my dissertation to my spectacular husband, Dr. Luke T. Russell, who has been unconditionally and consistently supportive of me throughout the last seven years of doctoral training. He is my soul mate, my mentor, and my best friend. I would also like to attribute my achievement to my encouraging parents who spared no efforts to raise me and send me to the U.S. to receive further education. I would also like to show my appreciation to my entire in-law families who have shown their love and support in a multitude of ways.

Thank you to my academic colleagues and mentors who are also my friends and family who have invested in me and guided me throughout tough times. I will not have come this far without your support!

Finally, I would like to highlight the significant support that I have received from the directors, staff members, teachers and parents from child care centers where I recruited mothers for interviews. It has been such a privilege have your support and trust. 


\section{Acknowledgements}

Many thanks go to my academic advisor, Dr. Jean Ispa, who have invested in training me and guiding me to become a better scholar day by day, and year by year. Thank you for establishing a hopefully solid foundation for me.

I am also very thankful for Dr. Gustavo Carlo’s mentorship. Being challenged and mentored by you help me become more grounded in my work. Your advice on finding the niche and your unconditional support during my job search spoke volume how much you truly care about your students.

I would also like to attribute my achievement to Dr. Duane Rudy, who has been the expert in cross-cultural parenting research. With your help, I have become more well versed in knowing the important gaps in the field of autonomy support conducted crossculturally.

I am especially grateful for Dr. Candace Kuby, who has expanded my horizon in the filed of early childhood education and honed my skills in qualitative methodology. You are always solution and suggestion oriented and have shared your positive attitudes with me during tough times.

Special thanks belong to two of my research assistants Chen Ju and Jiang Jiang who helped me transcribe interviews, coding, inter-rater reliability check, and making sense of results. Your dedications will never go unnoticed. 


\section{$\underline{\text { Table of Contents }}$}

$\begin{array}{ll}\text { Acknowledgements } & \text { ii }\end{array}$

Table of Contents $\quad$ iii

List of Tables $\quad$ iv

List of Figures $\quad$ V

Abstract vi vi

Chapters

1: Literature Review 1

$\begin{array}{ll}\text { 2: Methods } & 17\end{array}$

3: Findings and Implications 29

$\begin{array}{ll}\text { References } & 52\end{array}$

Appendices

$\begin{array}{ll}\text { A - Screening Survey } & 71\end{array}$

B - Perceived Parental Autonomy Support Scale (P-PASS; Mageau et al., 2015)

$\begin{array}{ll}\text { C - Demographic Information } & 73\end{array}$

Vita 


\section{List of Tables}

Table 1. Participating Families’ Demographic Characteristics.

Table 2. Codes, Categories, Definitions, and Quotes.

Table 3. Autonomy Support Scale by Item, Mean, SD, Range, and the Number Items of "It Depends" in U.S. and China. 


\section{$\underline{\text { List of Figures }}$}

Figure 1. Repeated Measure ANOVA comparing autonomy supportive levels of four scenarios across the U.S. and Chinese cultures. 


\begin{abstract}
According to self-determination theory (Deci \& Ryan, 2002), autonomy is conceptualized as a sense of volition or agency. Much research indicates that parental autonomy support contributes to children's well-being and academic achievement among middle-class families with school age children or adolescents (Lekes, Gingars, Philippe, Koestner, \& Fang, 2010; NICHD, 2004; 2008; Niemiec et al., 2006). Research is scarce in understanding low-income parents' autonomy support and autonomy restriction behaviors with preschool children. It is also unclear whether and how parents support or restrict children's autonomy in various caregiving contexts, such as during mealtimes and pre-academic activities. This study helps address this topic via a mixed method design. Scenario-based interviews were conducted with 40 low-income mothers in the U.S. and China $\left(n_{\text {U.S. }}=20, n_{\text {China }}=20\right)$, followed by administration of Perceived Parental Autonomy Support Scale (P-PASS; Mageau et al., 2015). U.S. mothers and Chinese mothers were similar in terms of level of autonomy support and restriction. In addition, both U.S. and Chinese mothers', levels of autonomy support and restrictions differed across the four caregiving scenarios. The study thus identified how specific caregiving contexts may elicit specific autonomy supportive and autonomy restrictive behaviors by low-income mothers with young children in the U.S. and China.
\end{abstract}




\section{Chapter 1: Literature Review}

Self-determination theorists (SDT; Deci \& Ryan, 2002) have suggested that there are universal needs in human development. One specific proposal of SDT is that autonomy is one of the three basic psychological needs evident across human cultures that contribute to positive child development (Manzi, Regalia, Pelucchi, \& Fincham, 2012; Sheldon, Kasser, Houser-Marko, Jones, \& Turban, 2005). In SDT, autonomy refers to individuals' sense of volition, (i.e., sense of agency that one can act according to one's own interests; Deci \& Ryan, 2002; Whipple, Bernier, \& Mageau, 2011).

There is abundant evidence that caregivers' autonomy support contributes to children's psychological well-being and school achievement (e.g., Lekes, et al., 2010; NICHD, 2004; 2008; Niemiec et al., 2006). However, several researchers have found evidence that the ways parents grant autonomy support to young children differ across specific caregiving domains (Smetana, 1988), across cultures (Rudy, Sheldon, Awong, \& Tan, 2007; Yeh \& Yang, 2006), and according to the historical, social and political experiences of caregivers (Alwin, 1990; Goodnow, 1985). Understanding of parental autonomy support strategies in children's early childhood across cultures remains largely understudied in the current developmental and cross-cultural research literatures. In one exception, Mosier and Rogoff (2003) compared how young children were treated in the U.S. and in the Guatemalan Mayan culture. They found that Mayan mothers of toddlers allowed them considerable freedom to act as they wished because mothers assumed that such young children cannot fully understand rules yet. U.S. mothers, on the other hand, believed that young children should follow fairness rules the same as their older siblings. Given that the Mayan culture is collectivistic this might suggest that caregivers in 
collectivistic countries (including China) may grant more autonomy to their young children than their U.S. counterparts.

Family social class may also affect parental endorsement of autonomy support. Much of the previous research on autonomy support has focused on middle-class parents' behaviors and values (Bernier, Carlson, \& Whipple, 2010; Cheung \& Pomerantz, 2011; Grolnick \& Ryan, 1989; Keller et al., 2007; Lekes et al., 2010; Matte-Gagné \& Bernier, 2011; Wang, Pomerantz, \& Chen, 2007). More research is needed to explore the extent to which low-income parents in various cultural contexts believe autonomy should be supported and how they say they would support their young children's autonomy.

Previous research on cultural differences has largely focused on comparisons between caregivers in individualistic (e.g., the U.S.) and collectivistic cultures (e.g., China; Markus \& Kitayama, 1991; Liu et al., 2005). The conceptualization and operationalization of autonomy supportive behaviors in these groups, however, has been inconsistent, and predominately focused on families in which parents are highly educated and economically well-off (Deci \& Ryan, 2002; Rudy et al., 2007). In an effort to extend research in this area and develop insights to address measurement challenges, I conducted a mixed-method study (Creswell, 2014; Yoshikawa, Weisner, Kalil, \& Way, 2013). I used a semi-structured interview with low-income mothers from the U.S. and China to elucidate their meanings and practices of autonomy support, plus a questionnaire on parental autonomy support (Perceived Parental Autonomy Support Scale; Mageau et al., 2015).

\section{Self-Determination Theory}


In SDT's broad framework (Deci \& Ryan, 2002), three basic psychological needs - autonomy, relatedness, and competence - are identified as universal regardless of culture. Autonomy support is demonstrated by parents when they respect children's perspectives, acknowledge their children's feelings, give reasons and explanations for rules, and provide guidance when needed (similar to scaffolding; Vygotsky, 1978). Autonomy supportive parenting practices have indeed been found to nurture children's sense of volition (i.e., that one can act in accord with one's sense of self, or one's own interests and values), and to contribute to children's emotional well-being in collectivistic as well as individualistic societies (Chirkov, Ryan, Kim, \& Kaplan, 2003; Lekes et al., 2010; Niemiec et al., 2006) and fosters learning and achievement (e.g., Cheung \& Pomerantz, 2011; Joussemet et al., 2005; Vansteenkiste, Zhou, Lens, \& Soenens, 2005).

Respecting autonomy does not mean letting children do all things on their own and being distant. Instead, it involves providing guidance when needed, giving explanations and reasons when talking about rules and goals, and acknowledging children's feelings and perspectives on, for example, their needs and preferences regarding mealtime and pre-academic learning. Autonomy supportive parenting is believed to facilitate children's ability to read parents' messages accurately, willingly and gradually internalize message from parents, and eventually achieve optimal integration with social-cultural structures (Deci, Eghrarl, Patrick, \& Leone, 1994; Grolnick, Deci, \& Ryan, 1997; Ryan \& Deci, 2002).

In SDT (Deci \& Ryan, 2002), caregivers' autonomy support depends on their trust in organismic development, which is based on a belief that human beings have natural developmental tendencies for positive growth and actively fit themselves into their social 
structures and cultural contexts. When parents have trust in organismic development, they are likely to respect their children's sense of volition, believing that children's perspectives are important and that children's autonomy should be respected (Deci \& Ryan, 2002).

\section{Autonomy Support across Cultures: U.S./Canada and China}

Culture influences parenting (Bornstein \& Cheah, 2006). According to SDT, the benefits of autonomy are universal, though there is evidence that the ways caregivers express autonomy support might vary across cultures (Deci \& Ryan, 2002). Caregivers’ concerns about children's autonomy regarding clothing, eating behaviors, and language use generally reflect their beliefs about what is culturally appropriate (or inappropriate). The importance of autonomy and how autonomy is supported might differ among parents with different cultural beliefs. In recent years, scholars have investigated specific types of autonomy to better understand autonomy through a cultural lens.

One of the earliest and most commonly proposed distinctions made across cultures is in regards to the concepts of individualism and collectivism (Markus \& Kitayama, 1991). Individualistic cultures are characterized by independent views of self wherein there is a clear boundary between self and others, including close others. In contrast, individuals in collectivistic cultures are presumed to emphasize an interdependent self. As a result, within collectivistic cultures, trusted others (in-group members such as family members and friends) are especially likely to have strong influences on decision making.

Researchers have found different levels of parental autonomy support in individualistic as compared to collectivistic cultures. For example, there is evidence that 
Chinese Canadian mothers show less encouragement of toddlers' autonomy (taking initiative and exploring during the free-play session) than their European Canadian counterparts (Liu et al., 2005). Similarly, Lekes and colleagues (2010) found that according to their adolescent children, U.S. and Canadian mothers' autonomy support levels were much higher than Chinese mothers' autonomy support level. While these studies speak to cultural difference in levels of autonomy support, we know less about cultural variation in the specific strategies parents use to support autonomy or the situations in which they think autonomy support is beneficial or harmful.

\section{Cross-cultural comparisons of child outcomes associated with autonomy}

supportive parenting. In a landmark study that challenged SDT, Iyengar and Lepper (1999) discussed how self vs. other task-selection influenced children's task performance and play preferences. Ivengar and Lepper (1999) found that Asian children spent more time playing an anagram game during a free play session and performed the best on a subsequent task involving the game when they knew it was their mothers who had chosen the activity. This suggested that children from collectivistic cultures enjoyed the choice made by a trusted other more than that made by themselves. In contrast, children from individualistic cultures embraced the choice they themselves made more than that made by their mothers. Children in individualistic cultures and collectivistic cultures might thus have different self-systems. Iyengar and Lepper (1999) suggested that personal choices might be more important for individuals in individualistic cultures than for individuals in collectivistic cultures. Rudy and colleagues (2007) found two kinds of autonomy support perceived by children based on their relative autonomy index scores (RAIs). They are perceived inclusive autonomy (e.g., “... in my family, we think it's what 
you are supposed to do,”) and individual autonomy (e.g., “...think it's what I'm supposed to do."). They found that inclusive RAIs were associated with Chinese Canadian's wellbeing (positively with self-actualization and negatively with depression), but were unrelated to European Canadian college students' well-being. Conversely, individual RAIs were related to self-esteem only among European Canadians. Given these findings, several researchers have suggested that more research needs to be conducted regarding how different ways of supporting autonomy may occur across different cultural contexts (Deci \& Ryan, 2002; Rudy et al., 2007).

Deci and Ryan (2000) argued that cultural variation in how values are transmitted may help explain why East Asian children are more accepting of choices made by trusted in-group members than their European American counterparts. However, they also cautioned researchers against too much relativism, noting that it is important to be mindful of within-group variation in the extent to which cultural values are integrated within the self. For example, genital mutilation is likely not valued by all members of a culture even if it is widely practiced in that culture.

Miller and colleagues (2011) argued that it is not that having choice is not important for individuals from collectivist cultures. Rather, researchers must understand how choice is perceived and consider the extent to which social expectations are internalized by people in individualistic as compared to collectivist cultures. In agreement with an earlier meta-analysis conducted by Oyserman, Coon, and Kemmelmeier (2002), Miller, Das, and Chakravarthy (2011) also described the centrality of duty, obligation, and sacrifice to in-group members in collectivist cultures. Miller and colleagues (2011) suggest that agentic choice must be understood within the context of internalized social 
expectations. They contend that duty to in-group members in particular is experienced as more autonomy-based by people from collectivist cultures (in this case, India) as compared to people from individualistic cultures (such as the U.S). Among collectivistic people, when duty is highly internalized, behaving in accord with duty is experienced as volitional, not forced by others. Thus, fulfilling duties can be felt to be highly autonomous instead of forced. Such internalization may also explain why as long as their idea concurs with that of trusted in-group others, individuals feel autonomous instead of controlled. In other words, despite the fact that individuals may appear to be engaging in collective action, psychically it may in fact be experienced as an autonomous expression of agency. Of course the content of duty and obligation vary across cultures (Miller et al., 2011). The strategies that parents use to facilitate internalization vary as well. For example, there may be variations in the extent to which parents provide agentic choices and reasoning to make their children feel autonomous while they fulfill social obligations.

Yeh and Yang (2006) argued for two types of autonomy when studying Chinese adolescents: individuating and relating. Yeh and Yang's individuating autonomy ("I always feel confident about my own decisions") emphasize individual's choices. In contrast, consideration of family relationships when making decisions involves Yeh's and Yang's relating autonomy ("When making a decision, I evaluate the practicalities of both my ideas and my parents' suggestions"). Yeh and Yang (2006) found individuating autonomy was more strongly related to adjustment in personal domains than relating autonomy, whereas relating autonomy was more strongly related to adjustment in interpersonal domains than individuating autonomy. 
The strength of the association between autonomy support and individual wellbeing has also been examined in cross-cultural research. In some studies, associations between autonomy and well-being are similar among U.S. and Chinese participants. For example, Wang and colleagues (2007) reported that in both China and the U.S., $7^{\text {th }}$ graders' perceptions of their parents' autonomy support (via choice making: "my parents allow me to make choices whenever possible," and opinion exchange: "my parents encourage me to give my ideas and opinions when it comes to decisions about me") were negatively related to emotional ill-being (worries, anger, depression) and positively related to grades over one academic semester. There was no difference in the strength of this effect on U.S. and Chinese children. However, autonomy support was related to increased goal investment only in U.S. children. Lekes and colleagues (2010) also found that Chinese and North American adolescents' perceived autonomy support, measured with the Perception of Autonomy Support Scale (sample item: My parents listen to my opinion or perspective when I've got a problem;" Robbins, 1994) was associated with adolescents' intrinsic goals and well-being (affect and self-concept).

\section{Autonomy Support across Domains in Early Childhood}

According to Smetana (1988), parents may grant different degrees of autonomy in different life domains. In the current study, caregivers with young children will be asked about their childrearing practices in two domains: mealtime and pre-academic learning. I have chosen to focus on mealtime as one of the caregiving domains due to evidence that nutrition and eating-related routines are among the most prominent childrearing concerns of mothers of young children, at least in the U.S. (Connell-Carrick, 2006; O'Brien, 1996; Porter \& Ispa, 2013). The domain of pre-academic learning is also included because 
several cross-cultural comparative studies of autonomy support have focused on school achievement due to the interest it holds for parents, professionals, and policy-makers (e.g., Cheung \& Pomerantz, 2011; Grolnick \& Ryan, 1989; Vansteenkiste et al., 2005).

There has been insufficient attention to variation in autonomy supportive strategies in different caregiving contexts. Suggestive evidence that parenting strategies differ across caregiving context can be found in a recent study. Fung and colleagues (Fung, Li, \& Lam, 2017) explored what mothers said they would do when their young children were acting out in various situations. They found that not only did mothers say they would use different strategies (e.g., power assertion, reasoning, and conflict avoidance) depending on factors such as where misbehavior happened, its possible consequences, and the degree of conflict, and some of them said they would use more than one strategy. Moving forward, it is worth exploring whether and how autonomy supportive or restrictive strategies vary across different caregiving contexts with both Chinese and the U.S. mothers.

\section{Changing Parenting Beliefs in the U.S. and China}

Today's U.S. and Chinese parents of young children may hold slightly different parenting values than caregivers from previous generations. Not only were there generational changes in both countries in the importance of supporting children's autonomy; also young parents (in their 20s and 30s) in both countries might have more positive attitudes towards the other country (Wike, 2016; Pew Research Center) than older generations in both countries. Today's parents of young children are more likely than their parents to be exposed to and influenced by globalization, suggesting that cultural values and parenting values of today's mothers with young children might have 
changed since data were collected for previous studies. Therefore, it is of great importance to explore and understand today's Chinese mothers' autonomy support instead of assuming that data collected a few decades ago reflects contemporary values and goals among young mothers.

The key goals outlined in the Declaration of Independence are life, liberty, and the pursuit of happiness. These values are passed down from generation to generation in the U.S., and constantly intertwine with the influences of technological, societal and economic vicissitudes. Wright and Wright (1976) found that between 1964 and 1973, U.S. parents' preferred qualities in children changed, with decreasing valuing of obedience or conformity and increasing valuing of self-direction or autonomy. Later, Alwin (1989) replicated Wright and Wright's research and found a similar pattern of change from 1964-1984. It is likely then that there are be generational changes in the ways children's autonomy is supported. Also, contemporary research comparing autonomy support in U.S. and Chinese families was conducted predominately with parents of school-aged or teenage children (Cheung \& Pomerantz, 2011; Lekes et al., 2010). There remains a need to understand how the views and strategies supporting or restricting autonomy are similar or different among Chinese and U.S. mothers of young children.

In China, parents' desired qualities in children seem to have recently changed from valuing shyness to valuing assertiveness (Chen, Rubin, \& Sun, 1992; Liu, Chen, Li, \& French, 2012), and, among affluent families with educated parents, from valuing obedience to valuing independence (Park \& Lau, 2016). Zeng and Greenfield (2015) compared frequencies of certain words in Chinese children's books and found that words 
that reflected collectivistic values decreased in frequency during the period between 1970 and 2008. This change might be related to China's urbanization, along with increasing educational opportunities and income levels occurring in the context of economic reform. In cross-cultural research on parenting, overwhelmingly, Confucius is referred to as the dominant influence on Chinese culture and parenting. Confucianism contends that cultivation is necessary to achieve five virtues or moral standards: ren (generosity and selflessness), yi (loyalty), $l i$ (politeness and respect), zhi (wisdom), and xin (trust). Filial piety is another important belief that is rooted in Confucianism, which includes the values of intergenerational caring, familial and societal hierarchy and patriarchy with the endorsement of interdependent social relationships (Dai \& Dimond, 1998). However, after the "new" China was founded by the Communist party in 1949, Confucian values were not highly endorsed because they were perceived as conflicting with Maoist theoretical perspectives. The antagonistic attitudes against Confucian values peaked during the Cultural Revolution. However, social scientists have argued that there is evidence of a resurgence of Confucian values in the most recent years (Ji, 2015). Many classics on parenting and morality that were heavily influenced by Confucianism have witnessed a revival. Examples include Di Zi Gui (Standards for being a Good Pupil and Child; Li, during Qing dynasty), Classic of Filial Piety (400 BCE), and Three Character Classic (Wang, during Song dynasty \& Ou, 1234-1324). My impression, based on what I have read on the Internet, in the news, and on WeChat (a widely used App in China), is that these books have become increasingly popular among parents and teachers. As suggested by Russell, Crockett, and Chao (2010), cultural values are introduced and reinforced through popular media. Values of filial piety, following rules, obedience and 
hierarchy are some of the main messages in these classics. When talking to parents in China, my impression is that along with the revival of traditional values, today's Chinese mothers with young children are also frequently exposed to mass media reports on U.S. standards on how to be good parents. Given the current mix of traditional Confucian values together with U.S. influence, caregivers in Chinese mothers might be rather conflicted regarding the value of autonomy support during everyday childrearing practices.

\section{Accounting for Socioeconomic Status}

Though a handful of studies suggests the benefits of parental autonomy support for children in low-income families (e.g., Ispa et al., 2015), most of the research samples in studies of autonomy support have focused on middle or upper-middle class families (Bernier et al., 2010; Cheung \& Pomerantz, 2011; Grolnick \& Ryan, 1989; Keller et al., 2007; Lekes et al., 2010; Matte-Gagn et al., 2011; Wang et al., 2007; Whipple et al., 2011). There is substantial evidence that low-income families face more struggles than middle-class families in meeting the developmental and security needs of their children (Evans \& Kim, 2013; Rubin, 1994; Seccombe, 1995).

Previous research demonstrates that low-income families in the U.S. have strong desires to help their children negotiate unsafe neighborhoods with limited resources, and these parents are therefore more likely to enforce strict parent-child boundaries, more likely to use directives, and less likely to use reasoning than middle-class parents (Hoff, Laursen, \& Tardif, 2002; Hoff-Ginsberg, 1991; Lareau, 2011). Lareau (2011) has also argued that children in poor and working-class families are not encouraged to negotiate on their own behalves. She suggests that low-income parents are less likely than their 
middle-class peers to elicit their children's thoughts and opinions, in part because they are preparing their children to subordinate to institutional authority. In other words, they want their children to be prepared feel satisfied in life even in the context of low sense of control. Research conducted in the U.S. has regularly shown that parents from low socioeconomic status households are less likely to have egalitarian parent-child relationships than parents in middle-class families (Gecas, 1979; Hess, 1970). They also tend to show lower levels of autonomy support than their middle-class counterparts (Bayley \& Schaefer, 1960; Bradley, Corwyn, McAdoo, \& Garcia Coll, 2001). Researchers have likewise found that Chinese mothers in low-SES (indicated by occupation and education) families tend to be more authoritarian - more likely to discourage children's emotional expressions and use power-assertive discipline practices than parents with higher levels of education and occupations with higher social rankings (Chen, Dong, \& Zhou, 1997).

However, Wiley and colleagues' research (1998) in the U.S. suggests that lowincome parents may believe that they also support children's autonomy, though the practices they use to support it may be different than those employed by middle-class parents. Middle-class mothers in their study seemed to believe that it was children's natural right to express their perspectives, whereas parents from low-income families seemed to believe that autonomy should be earned and defended by children. Understanding low-income U.S. mothers' views on practices that are autonomy supportive, and whether low-income Chinese mothers' practices and views are similar or different from those of U.S. mothers can provide further insight regarding the universality of self-determination theory. This will support the development and use of culturally- and 
contextually-appropriate measures. Cross-cultural research comparing Chinese and U.S. mothers in terms of parental autonomy has also mainly involved families from middleclass backgrounds living in metropolitan areas (Liu et al., 2005; Manzi et al., 2012; Wang et al., 2007; Wang, Chan, \& Lin, 2012). It is unclear to what extent low-income parents living outside of major metropolitan areas support their young children's autonomy.

\section{The Current Study}

In this study, I explored what mothers from low-income families in the U.S. and China said they would do in four different situations involving their young children. Their responses were analyzed in terms of the autonomy support or restriction of the childrearing strategies they said they would implement with their young children. Historically, mothers have spent more time than fathers taking care of their children (Bianchi, 2000). Therefore, I limited my sample to mothers in both countries. The U.S. and China are often held-up as prototypical examples of individualistic and collectivistic cultures, making these samples particularly interesting to compare. I chose to examine childrearing strategies used with young children (ages 3 to 7 ) because early childhood is such a fundamental developmental stage of life. Quality parenting in early childhood contributes to children's developmental competencies (Ispa, Su-Russell, Palermo, \& Carlo, 2017), well-being, and relationship with parents later in life (e.g., Ispa et al., 2015).

I collected data primarily through semi-structured interviews consisting of discussions of two hypothetical scenarios about mealtimes and two hypothetical scenarios about pre-academic learning situations, each followed by probing questions. This format allowed mothers to describe what they would do to support or restrict children's 
autonomy during mealtime and pre-academic learning contexts, and why. Using mixed methods (Creswell, 2014) allowed me to not only explore in-depth responses from the mothers, but also to get numeric responses and comments on existing measures of autonomy support (in this case, a measure adapted from the Perceived Parental Autonomy Support Scale; P-PASS; Mageau et al., 2015), P-PASS assesses the extent to which parents say they would support their young children's autonomy. The study was guided by the following research questions:

Research Question 1: How do U.S. and Chinese mothers say they would support or restrict their young children's autonomy?

Research Question 2: Are Chinese and U.S. mothers similar or different in terms of autonomy support and restriction?

Research Question 2a: Do mothers in China and the U.S. differ in their levels of support and restriction of their young children's autonomy in each of the four scenarios?

Research Question 2b: Are Chinese mothers and U.S. mothers different or similar in their numeric responses to the Perceived Parental Autonomy Support Scale? Research Question 3: Is mothers' level of endorsement of autonomy support on the Perceived Parental Autonomy Support Scale related to their autonomy support and restriction levels as reflected in their scenario-based interview responses? Do these relations differ between U.S. and Chinese mothers?

Research Question 4: Are there any differences in the levels of autonomy support and restriction across the four scenarios? 
Research Question 5: Are scores on the Perceived Parental Autonomy Support

Scale related to autonomy support and restriction levels determined from responses to the four scenarios? 


\section{Chapter 2: Methods}

\section{Participants}

From January to August, 2017, I recruited 20 mothers from the U.S. and 20 mothers from China $(N=40)$. The 20 U.S. mothers were recruited from six early childhood childcare centers in a Midwestern college town. Three of these centers included families from both low-income and middle class families. The other three centers are Head Start programs. Participants met the following criteria: (1) Mothers had at least one child between the ages of 3 and 7. (2) Mothers were living with their children. (3) Participating families must have had family income less than twice the federal (U.S.)/national (China) poverty line.

The study sample included 9 U.S. mothers of girls, 11 U.S. mothers of boys, 13 Chinese mothers of girls, and 7 Chinese mothers of boys. Building on existing crosscultural research on autonomy support, it seems comparisons might be more likely to occur in samples that are European Americans in the U.S. and Chinese in China. When I was making decisions on the U.S. sample, my goal was to recruit low-income European Americans. However, when I started recruiting from child care centers, I realized that by limiting my sample to a White-only sample, I would be creating a sample that does not reflect the diversity that is typical in child care centers that serve low-income populations in much of the U.S. Therefore, I decided to recruit low-income mothers regardless of their racial backgrounds ( $n$ white $=8, n$ Black $=9, n$ Latina $=3$ ). For other descriptive statistics on mothers' education, marital status, income, employment, and number of people living together, see Table 1. 
Chinese mothers often laughed at me or were surprised to hear my question when I asked them their marital status. They usually said something to the effect of, "Of course I am married; I have a kid; I am not that "open-minded" (kaifang). This was not the case for the U.S. participants. At the time when data were collected, the U.S. sample included participants who were married $(n=7)$, single $(n=7)$, divorced $(n=1)$, and cohabitating with their partners $(n=5)$.

\section{Recruitment Process}

Participants who met the previously mentioned criteria were recruited from local child care centers in one selected city from each country. Specifically, to obtain the U.S. sample, I made connections with the directors at selected early childcare/preschool centers through my academic advisor. To obtain the Chinese sample, I used personal connections. In both countries, the child care centers from which I drew participants provide high-quality care, have state/province level equivalent accreditations, and serve families from low-income backgrounds. In each city, there are higher education institutions, hospitals, and public transportation. The city in the U.S. had a population of 120,612 in 2017 (U.S. Census Bureau, 2017), and the city in China had a population of 2,787,032, with 531,000 living in the city proper in 2007 (Wikipedia).

I started by recruiting the U.S. participants from four centers, three of which serve only low-income families. One is open to both low-income and middle class families. I then added two more centers to increase my sample. The last two centers include children from various income levels.

Once I received permission from the directors to recruit participants, I submitted my research proposal to the University of Missouri Institutional Review Board (IRB). As 
soon as I gained the IRB approval, I started recruitment in the U.S. and China simultaneously. In the U.S., I began by making folders that each included a recruitment flyer, a pre-screener consent form, and a screening survey (Appendix I). I prepared a total of 145 folders for all six centers. Directors and their assistants were very supportive of my recruitment efforts and welcomed me when I asked to spend some time during dropoff and pick-up times to recruit participants. At almost all of the six centers, I spent at least one morning or afternoon during drop-off or pick-up times in preschool classrooms trying to talk to parents who might be interested in the study. To start off, I introduced myself and the purpose of this study, and told parents that to compensate their time, I would give them a $\$ 10$ gift card. At the beginning of the recruitment period, as I was first contacting parents, I got the sense that their days were often packed or subject to change, as they were working multiple shifts or shifts that were unpredictable.

As I learned this, I started telling parents that I could drive to their homes or work places, and I could also meet with them over the weekends. I could tell by their reactions that this surely made participation in interviews more appealing and feasible. This was an enriching process from which I learned quite a lot, such as the importance of sending out reminders just in case participants had to reschedule (again), the necessity of preparing myself for disappointment for no-shows or rescheduling, and the need to bring with me extra documents such as consent forms for participants' families and friends who might spontaneously join the interview. Once I confirmed the eligibility of participants, they were contacted via text messages, sometimes multiple times; through phone calls and voicemails; or in person at pick-up or drop-off times. Many of these contacts did not result in an interview. Occasionally, agreed-upon meeting times for interviews had to be 
rescheduled. A firm decision made jointly by the participant and myself on a feasible time that was specific and a convenient meeting place (usually their homes) proved to be the most successful way to ensure that an interview would actually occur.

All the recruiting documents, consent forms, and surveys were first finalized in English. I then translated these documents into Mandarin Chinese. I asked one of my colleagues who is a bilingual female professor to back translate these documents from Chinese to English. We compared and contrasted any discrepancies until we reached agreement that these documents were equivalent across both languages.

Recruitment in China, via the strong support of the child care center director and to some extent due to the importance of authority, was considerably smoother. I had a personal connection with the director, and her assistant organized parent-meeting to introduce this project and ask parents to leave contact information. There were two rounds of recruitment from this child care center. Each time 20 parents were contacted by the director's assistant. This resulted in 20 parents total agreeing to participate in the study (50\% success rate). Once the parents got my contact information (my WeChat username), a few added me in their WeChat. For most of the parents, I initiated the contact with them by adding them as my friends and leaving a message letting them know who I am and the purpose of this study. Scheduling a time that worked for both the participant and myself was difficult at times due to some parents' lack of awareness of the time zone difference and limited availability. Getting up in the morning at 5:30 a.m. was a norm during the weeks when I was collecting data with Chinese participants.

\section{Data Collection Procedure}


Data collection took place virtually via WeChat with Chinese mothers. I

interviewed the U.S. mothers in their homes, at fast food restaurants, and at the child care centers during pick-up times. Mothers who were teachers were interviewed during their breaks. Interview locations varied for the U.S. participants. Both groups were free to decide where (and when) was the most convenient and comfortable location (and time) to participate in the interviews. This is recommended practice that is justice-oriented for interview based research (Holstein \& Gubrium, 1995). At the start of each session, I usually conversed with the mothers informally and introduced myself. I then gave a brief overview of the purpose of the study and the agenda of the interview, which include four scenarios, followed by open-ended questions, then the questionnaires, and finally a series of demographic questions.

I started my interviews by reading out loud four scenarios (described below), one at a time, and asked mothers to tell me how they would respond to each of the hypothetical situations. Next, I administered the Perceived Parental Autonomy Support Scale (P-PASS; Mageau et al., 2015). I also asked mothers to write their comments and reactions regarding the items in each instrument. Interviews and surveys were conducted in English with U.S. mothers and in Mandarin Chinese with Chinese mothers. Finally, after the questionnaires were completed, I asked the participants some demographic questions regarding their marital status, employment status, and educational levels. Interviews ranged in length from 30 to 60 minutes.

The interview protocol and examples provided below are in English. U.S. mothers responded to the questionnaires by writing down numeric responses. Their comments on the questionnaires were either recorded or written on the questionnaires. For Chinese 
mothers, I read each item of all the questionnaires and the demographic questions to them in Mandarin Chinese. I recorded their responses and comments in a Word document and saved and secured in my computer.

The four scenarios. Semi-structured interviews proceed much like a normal conversation, in which there is a rich opportunity for the interviewer to ask questions. My questions were phrased so as to help me determine the extent to which caregivers supported autonomy during mealtime and pre-academic learning, and the practices they employed that supported (or hindered) children's autonomy development. During these one-on-one interviews, I asked questions to try to understand mothers' rationales for implementing or not implementing autonomy supportive practices. This allowed me to share participants' perspectives as part of my findings (Creswell, Klassen, Plano Clark, Smith, \& the Office of Behavioral and Social Sciences Research, 2011).

I developed four scenarios and open-ended questions about caregiving practices during mealtime and pre-academic learning to elicit mothers' thoughts about autonomy supportive and autonomy restrictive childrearing strategies. I began this segment of the interview by explaining that I was curious as to learn what they do as parents with their children in everyday activities.

Scenarios. Below are a series of day-to-day scenarios that many families encounter at mealtime and during pre-academic learning activities. These scenarios were used during semi-structured interviews in order to elicit mother's beliefs regarding her role in supporting (or limiting) child's autonomy. Examples of autonomy supportive behaviors involve respecting child's voices, acknowledging child's feelings, offering reasons and guidance. 
Mealtime scenarios. (1) Imagine you are at the dinner table, and your family is having noodle soup tonight. What if [Child's Name] wants to mix something sweet into the noodle soup and you don't think this would be a good idea? What would you say and do and why? (2) [Child's Name] does not want to eat lunch, but you are not planning to have another meal until much later in the day and suspect [Child's Name] will get hungry before then. What would you do and say and why?

Pre-academic learning scenarios. (1) You see [Child's Name] building towers with blocks with one block on top of the other, but you are thinking the tower is going to fall if it is built in [Child's Name]'s way. What would you say and do and why? (2) [Child's Name] is reading a book about animals, as [Child's Name] is reading the page about ducks, [Child's Name] makes the sound that you don't think sounds like a duck's quacks, but more like a pig's oinks. What would you say and do and why?

Probing. During my interview, I kept a copy of the interview protocol, with the key words highlighted, to make sure every participant got the chance to answer most of the questions, if not all. Most of the times, participants provided adequate responses to the scenarios. I also used follow-up questions to further probe participants' responses to the scenarios. Example probes were as follows:

1. How do you get [Child's Name] to listen to you when [Child's Name] disagrees with you about meals (e.g., how prepared, food choices, timing of snacks and meals)? What kinds of things does [Child's Name] say? When that happens, what would you say to [Child's Name] and why?

2. Do you think it is important to get [Child's name] to build with blocks the way you think is the best way? Why is that? 
More open-ended questions were spontaneously generated to follow up on or clarify caregivers' responses. Some examples were:

1. What are some of the common conflicts/fights/arguments/disagreements at mealtime, and pre-academic learning activities you have with your child? And how do you usually handle it?

2. Could you describe some situations where you think it is important for children to want to do what they are supposed to be doing?

3. Are the situations where it is not as important to have children want to do what they are supposed to be doing?

4. Sometimes children do things they shouldn't do, what are some such situations you have experienced? How have you handled [a certain situation that Mother describes]?

Sensitizing concepts. Based on previous research, I had sensitizing concepts (Blumer, 1986) in mind as I operationalized how mothers might support children's autonomy (e.g., Grolnick \& Ryan, 1989; Grolnick, Gurland, DeCourcey, \& Jacob, 2002; Whipple et al., 2011). These sensitizing concepts led me to the following operational definitions of autonomy support: (1) Reasoning: Mother offers reasons to the child for setting limits and rules. (2) Suggestions: Mother offers suggestions to her young children when children's decisions might have negative consequences. (3) Respect Ideas: Mother values and respects children's voices. When children tell stories, share opinions, mother respects children's ideas and opinions. Mother is positive and respectful towards children rather than ignoring, mocking, or defying children's ideas, or opinions. (4) Mother acknowledges and cares about children's feelings. (5) Guidance and mentorship: Mother 
offers guidance rather than leaving children to do everything on their own when she sees children struggle and frustrate themselves. The goal of giving guidance, suggestions or scaffolding should be to help children learn and eventually become capable of accomplishing the tasks on their own.

I constantly adjusted and improved my interview techniques as I interviewed more parents, trying out different wording, being more cognizant of leading questions, and using different levels of probing. These were dependent on how much each participant was willing to share and wanted to talk. Though I wanted to use the interview protocols to guide me and probe with all the open-ended questions on the list, the real interviewing processes were not like a script that could be planned as if in a template. During the data collection process, I noticed that sometimes parents were struggling to comprehend the open-ended questions that were in my interview protocol. I adjusted wording of the questions based on participants' interpretations of the questions, so they could share their thoughts in response to those questions.

An initial coding scheme was created based on the sensitizing concepts from SelfDetermination Theory (Deci \& Ryan, 2002) and agreement between my advisor and me. Definitions of each code were revised as needed. Then, I trained my research assistants to code the rest of the interviews based on the same coding scheme, following the constant comparison method. We met regularly throughout summer of 2017 to give my RA transcribing and coding assignments. When we started the coding process, my RA and I coded each participant independently. We used the sensitizing concepts but did not limit ourselves to the coding scheme. Each time, I randomly selected four participants for us to code independently. The following week, we met to discuss our codes in each scenario of 
each participant. We looked for agreements and disagreements in our coding. Disagreements were resolved through discussion and reference to the sensitizing concepts and how autonomy is conceptualized in the Self-Determination Theory (Deci \& Ryan, 2002). Discussions on coding continued until coders reached agreement on the selected transcripts. I coded the rest of the transcripts based on the agreed-upon coding scheme. The final coding scheme is presented in Table 2.

Questionnaires. The Autonomy Support questionnaire used in the current study was adapted from the Perceived Parental Autonomy Support Scale (P-PASS; Mageau et al., 2015). P-PASS was used to assess youths or young adults' perceptions of their parents' autonomy support. In the current study, my participants were mothers of young children. In order to capture mothers' perceptions of their autonomy support to their young children, I changed the subject of each statement from "My parent" to "I." The scale is comprised of 12 items assessing endorsement of autonomy support from 1 (strongly disagree) to 7 (strongly agree) (sample item: "When my child asks why s/he has to do, or not do, something, I give him/her good reasons."). In the current study, the Cronbach's alphas for the 12-item instrument were .70 and .64 for Chinese and the U.S. groups respectively. In order to enhance inter-item reliability, especially for the U.S. group, I dropped two items ("I am able to put myself in my child's shoes and understand his/her feelings," and "I hope that my child would make choices that correspond to his/her interests and preferences regardless of what mine are.”). The 10-item Cronbach's alphas were .72 and .71 for the U.S. and Chinese groups respectively. An average score was created based on these 10 items for the Chinese group and the U.S. group. These two P-PASS averaged scores on were used in the analyses $\left(M_{\text {U.S. }}=6.18, S D_{\text {U.S. }}=.58 ; M_{\mathrm{CH} .}=\right.$ 
$\left.6.32, S D_{\mathrm{CH}}=.62\right)$. In previous research, P-PASS was mainly used among European descendent participants (Costa, Cuzzocrea, Gugliandolo, \& Larcan, 2016; Mageau et al., 2015; Mageau Bureau, Ranger, Allen, \& Soenens, 2016; Won \& Yu, 2018) with decent Cronbach's alpha levels ( $\alpha$ s > .83) (Costa et al., 2016; Mageau et al., 2015; Mageau et al., 2016; Won \& Yu, 2018). In these studies, scores predicted life satisfaction $(\beta=.45)$ (Mageau et al., 2015), and negatively related to college students' procrastination $(\beta=$ -.27) (Won \& Yu, 2018). (The questionnaire is shared in Appendix II.)

Relevant demographic information was collected after the semi-structured interviews and administration of the P-PASS questionnaire. The questions are in Appendix IV.

\section{My Social Position as an Interviewer}

I am a bicultural and bilingual person, born and raised in China, but in the U.S. for the last seven years for graduate training. I am familiar with both Chinese and U.S. cultures, and am married to an American of European descent. I am thus simultaneously an insider and outsider of both cultures. When I interviewed Chinese mothers, I had the impression that cultural norms may have changed in the last few years, especially in regards to childrearing beliefs, and therefore, I might not know what the norms are today. When interviewing mothers in the U.S., I recognized my limited experiences in the U.S. My experiences may have allowed me to easily build rapport with individuals from both groups because I was honest with participants in both countries that I had a lot to learn about their childrearing practices.

\section{Data Analysis}


Mothers' responses to scenarios and open-ended questions were transcribed and inductively analyzed following constant comparison strategies (Corbin \& Strauss, 2014). NVivo, a software program, was used to manage the qualitative data (Gibbs, 2002).

I hired two bilingual graduate research assistants who were Chinese international students in graduate programs at the University of Missouri. My research assistants and I shared the transcribing responsibilities. One RA stopped working on this research due to her internship in a different town. The other RA consistently worked on this research by transcribing, coding and interrater reliability discussions. During the coding phase, my advisor and I independently read through the raw texts and highlighted relevant text indicative of the extent to which mothers said they supported or limited children's autonomy. We were independently looking for key indicators such as the extent to which they respected child interests, decisions, choices, ideas, and offered guidance and reasoning (Grolnick \& Ryan, 1989; Grolnick et al., 2002; NICHD, 2004; Whipple et al., 2011). We independently developed codes according to the operational definitions of autonomy and met every other week to discuss our codes and debrief on our open coding process. New codes were constantly compared with codes developed previously. When we met, we discussed our disagreements across the codes. The list of codes were adjusted by comparing similarities and differences among old codes and new codes to make sure the same concept was put under the same code. 


\section{Chapter 3: Findings and Implications}

\section{Research Question 1: How do U.S. and Chinese mothers say they would support or restrict their young children's autonomy?}

In order to answer Research Question 1, I conducted inductive coding of mothers' responses to each scenario using the constant comparison method (Corbin \& Strauss, 2014). After reaching interrater agreement as described in the Method, I generated nine mutually exclusive codes to describe different ways mothers said they would support or restrict children's autonomy: The codes and their frequencies by U.S. and Chinese mothers in each scenario are presented in Table 2.

1. Mother lets child experiment: Mother allows or encourages child to explore, believing in the importance of trial and error.

2. Mother recognizes child's feelings: Mother is sensitive to and cares about child's feelings.

3. Mother respects child's views and agentic choices: Mother acknowledges and values child's perspectives and decisions in timing and methods for meal and/or learning activities.

4. Mother compromises: Mother provides or allows for alternatives that are acceptable to her while also taking into account child's preferences.

5. Mother explains: Mother provides reasons for why child should do certain things certain ways, or makes the rules and alternatives clear to children.

6. Mother teaches or helps: Mother tells child about her experiences and/or expresses willingness to provide information and strategies. 


\section{Mother does not let child experiment because it is against the norms, but} does not tell child why: Mother says she would not let child try out new things or new ways of doing things because it is not what people usually do.

\section{Mother does not let child experiment; says it is unhealthful, but does not tell} child why: Mother says she would not let child try out new things or new ways of doing things because mother is concerned about child's health.

9. Mother imposes agenda on child: Mother is in charge of routines and schedules of child's daily life, with little to no room for flexibility. After developing the nine codes, I conceptually grouped them into two larger categories: autonomy support (codes 1 through 6), and autonomy restriction (codes 7 through 9). Table 2 shows the number of Chinese and U.S. mothers whose responses reflected each of the nine codes. Below, for each of these nine codes, I share representative examples of specific autonomy-supportive and autonomy-restrictive strategies used by mothers in both countries. These examples provide further insight into the kinds of behaviors that were coded as fitting each of the categories.

Category 1: Autonomy support. The following six categories were included in the overarching theme of autonomy support.

Mother lets child experiment. Clear examples of maternal openness to child experimentation were illustrated most frequently in mothers' responses to Scenarios 1(Soup) and 3 (Blocks). For example, in response to Scenario 1 (Soup), four Chinese and seven U.S. mothers said they would let their children put sugar in the noodle soup because, “Children's ways don't have to be the same as adults', perhaps, children have curiosity," as shared by a Chinese mother. In response to Scenario 3 (Blocks), almost all 
mothers $(n \mathrm{CH}=16, n$ U.S.. $=18)$ said that they would allow for and/or encourage their children to experiment when building with blocks.

Mother recognizes child's feelings. Mothers' sensitivity to and acknowledgement of children's feelings was found in each of the four scenarios, but was illustrated most frequently in mothers' responses to Scenario 3 (Blocks). For example, nearly the same number of mothers in each country $\left(n_{\mathrm{CH}}=5, n_{\mathrm{U} . \mathrm{S}}=4\right)$ said that they would attend to children's feelings and come up with different strategies depending on how children would react to the falling of block towers. One Chinese mother reasoned, "[Child's name] would be very sad, frustrated, might throw tantrums," if block towers fell. That was why she said she would check in with her son to see how he reacted to unpleasant events like the falling of block towers.

Mother respects child's views and agentic choices. Mothers' emphasis on children's perspectives and decisions was found in each of the four scenarios. It was illustrated most frequently in mothers' responses to Scenario 2 (Lunch). For example, over twice as many U.S. as Chinese mothers $\left(n_{\mathrm{CH}}=6, n_{\mathrm{U} . \mathrm{S} .}=15\right)$ said that they would respect their children's thoughts and decisions, instead of forcing them to eat. A U.S. mother figure reasoned, "Cuz sometimes, just like you and me, we are not hungry at that moment."

Mother compromises. Mothers' flexibility in coming up with alternatives that take into account children's preferences was illustrated most frequently in mothers' responses to Scenarios $1 \& 2$. In response to Scenario 1 (Soup), about equal numbers of U.S. and Chinese mothers compromised $\left(n_{\mathrm{CH}}=12, n_{\mathrm{U} . \mathrm{S}}=10\right)$, among whom six mothers (two Chinese and four U.S. mothers) said that they would put a small portion of noodle 
soup in a separate container so their children could experiment to see if they liked it with sugar. This way, they reasoned, if their children did not end up enjoying how the sweetened soup tasted, they would not have wasted an entire bowl of the soup. One of these, a U.S. mother, said, "I am pretty open to letting him figure things out, and figuring out the consequence to his action. So he really insists on trying something sweet, then I would take a little bit out of the bowl, and he can mix his own, he can try that way." In response to Scenario 2 (Lunch), only a few mothers in each culture $\left(n_{\mathrm{CH}}=3, n_{\mathrm{U} . \mathrm{S} .}=5\right)$ said they would save lunch for their children and the children could eat it later, or they would figure out some other alternative options.

Mother explains. Mothers' explanations as to when or why children were not allowed or encouraged to do certain things were illustrated most frequently in responses to Scenarios $1 \& 2$. In response to Scenario 1 (Soup), 10 Chinese and one U.S. mother said that they would explain to their children why it was not a good idea to mix sugar in the noodle soup. For example, one Chinese mother said that she would tell her child, "[Eating sugar] will decay your teeth, like bugs in your teeth damaging your teeth. The bugs like sweets. Sweets would hurt your teeth.” In response to Scenario 2 (Lunch), one U.S. mother said she would explain to her children why they should eat lunch before going out, "We're going to the park, we're gonna use a lot of energy, and you know you really need to make sure that you eat something."

Mother teaches and helps. Mothers' emphasis on children's perspectives and decisions was found in each of the four scenarios, but was illustrated most frequently in mothers' responses to Scenarios 3 \& 4. For example, in response to Scenario 4 (Books), 11 mothers $\left(n_{\mathrm{CH}}=5, n_{\text {U.S. }}=6\right)$ said that they would take their children to see real animals 
or use the Internet and media resources to support their children's learning about animal sounds. This way, they reasoned, their children would learn how animals were supposed to sound via direct experiences. Another example of mothers' teaching and helping came from a Chinese mother's response to Scenario 3 (Blocks). She said this scenario happened in her home and that she would not intervene as her child was building the block towers. Instead, she would help analyze why her son's towers fell, such as telling him that the tower he had built lacked a solid foundation. Further, she said, "It is just like now mom guans ${ }^{1}$ you, and you think I guan you too much, not letting you do this and that. But if you are not setting up a solid foundation when you are a child, what is going to happen to you in the future? Without a solid foundation, your future life is going to be like this tower, falling apart." She used this opportunity to explain the importance of building a solid foundation for her son's life.

Category 2: Autonomy restriction. The following six categories were included in the overarching theme of autonomy restriction.

Mother does not let child experiment, it is against the norms. Mothers' prohibition of children's experimentation due to mother's beliefs that one should abide by the societal norms was evident in mothers' responses to Scenarios $1 \& 4$. For example, in response to Scenario 1 (Soup), seven mothers $\left(n_{\mathrm{CH}}=5, n_{\text {U.S. }}=2\right)$ said sugar shouldn't be added to noodles because it is not the way we eat noodles. Most mothers $\left(n_{\mathrm{CH}}=15, n_{\mathrm{U} . \mathrm{S}}=\right.$ 14) in response to Scenario 4 (Books) said they would correct their children if their children did not make the "quack" sounds, the correct sounds for ducks. As one U.S.

\footnotetext{
${ }^{1}$ Guan is a term to describe Chinese indigenous parenting that entails caring, training, and educating (Chao, 1994).
} 
mother reasoned, "It is important to me that she understands which sounds go with which animals."

\section{Mother does not let child experiment, says it is unhealthful. Mothers'}

restrictions regarding children's experimentation due to their concerns for children's health were found in their responses to Scenarios $1 \& 2$. This was the reason behind 13 mothers' $\left(n_{\mathrm{CH}}=6, n_{\text {U.S. }}=7\right)$ prohibitions around putting sugar in their noodle soup (Scenario 1 (Soup)). A U.S. mother said, "I really don't like him to have sugar because he's super hyper anyways." Another example came from a Chinese mother in response to Scenario 2 (Lunch), "I need to consider his health and want him to have a healthful habit. Good habits should be cultivated when children are young."

Mother imposes agenda on child. Examples of mothers enforcing strict rules on their children were reflected most frequently in mothers' responses to Scenario 2 (Lunch). Thirteen mothers $\left(n_{\mathrm{CH}}=9, n_{\text {U.S. }}=4\right)$ said their children were supposed to eat lunch at lunch time. A U.S. mother said she would respond to her child this way, "Then he doesn't eat. Then get away from the table, then go on and do something, you are not getting anything, and you are not gonna get a snack after, when it is snack time, because you didn't eat your lunch; you have to wait until dinner." A Chinese mother said, "It happened before, and he usually ended up eating his lunch. I told him if you don't eat your lunch right now, there won't be anything left later. Or it is going to be cold and I won't warm it up for you. Also, I will not change dinner time to 2 or 3 p.m. just because you start feeling hungry around then." She then reflected on her strategies and asked me if she was too harsh or authoritarian. 
Research Question 2: Are Chinese and U.S. Mothers Similar or Different in Terms of Autonomy Support and Restriction?

Research Question 2a: Do Mothers in China and the U.S. Differ in Their Levels of Support or Restriction of Their Young Children's Autonomy in Each of the Four Scenarios?

In order to answer Research Question 2a (whether Chinese and U.S. mothers differ in levels of autonomy support or restriction across the four scenarios), I conducted a 2-step analysis. Given that many mothers' responses included codes that belonged to more than one category, during the first step of the analysis I quantified the qualitative data by generating a numeric score for each mother's response in each of the four scenarios based on the following criteria. Maternal autonomy support was scored as 1 (low level autonomy support), if the response to a given scenario had been coded as fitting only in Category 2. Maternal autonomy support was scored as 2 (medium level autonomy support), if the response to a given scenario had been coded as fitting both Categories 1 and 2. Maternal autonomy support was scored as 3 (high level of autonomy support), if from the response to a given scenario had been coded as fitting only in Category 1. Thus, mothers' levels of autonomy support were indicated by three numeric scores $(1$ = autonomy restriction, 2 = medium level of autonomy support, $3=$ high level of autonomy support). Each mother received four scores, one for each scenario.

During the second step of the analysis, a one-way MANOVA was conducted comparing the Chinese and U.S. mothers' numeric scores for autonomy support or restriction level. Results revealed a nonsignificant multivariate main effect of culture, Wilks' $\lambda=.494, F(3,36)=.66, p=.582, \eta^{2}=.05$, power $=.175$. Thus, Chinese and U.S. 
mothers' levels of autonomy support or restriction did not differ in any of the four scenarios.

\section{Research Question 2b: Are Chinese Mothers and U.S. Mothers Different or Similar in Their Numeric Responses to the Perceived Parental Autonomy Support Scale Assessing Autonomy Support?}

In order to answer Research Question 2b, an independent samples $t$-test was performed comparing U.S. and Chinese mothers' average P-PASS scores based on the final list of 10 items (Mageau et al., 2015). The results showed that the U.S. and Chinese mothers did not differ $(p=.45)$ on their levels of autonomy support based on P-PASS. Table 3 presents means, standard deviations, ranges for each item, as well as the numbers of participants who had comments on the items.

\section{Research Question 3: Is Mothers' Level of Endorsement of Autonomy Support on the Perceived Parental Autonomy Support Scale Related to Their Autonomy} Support and Restriction Levels Reflected in Their Scenario-based Interview

\section{Responses? Do These Relations Differ between U.S. and Chinese Mothers?}

In order to answer Research Question 3, I conducted zero-order bivariate correlation tests to examine associations between the average scores based on the final list of 10 P-PASS items (Mageau et al., 2015) and average scores based on levels of autonomy-supportive practices indicated in response to the scenario-based interviews. No significant correlations were found between P-PASS average scores and scenario-based autonomy support or restriction levels in either the U.S. group $(\beta=.21, p=.37)$ or the Chinese group $(\beta=.42, p=.06)$. 


\section{Research Question 4: Do Levels of Autonomy Support or Restriction Differ Across Four Scenarios among U.S. Mothers and among Chinese Mothers?}

In order to detect whether mothers' autonomy support or restriction levels varied across scenarios within each group, I conducted a one-way repeated measure ANOVA separately for the Chinese mothers and the U.S. mothers.

First, a one-way repeated measure ANOVA was performed using the Chinese sample. Since Sphericity was violated [W (5) =13.76, $\mathrm{p}=.017$ ], the Greenhouse-Geisser correction was used. The results revealed that Chinese mothers' levels of autonomy support varies across the four scenarios, $F(2.07,39.32)=12.71, p<.001, \eta^{2}=.40$. Bonferroni post-hoc tests comparing Chinese mothers' responses to the four scenarios revealed that the level of autonomy support was higher in Scenario 3 (Blocks) $($ Mean = 3.00) than in Scenario 1 (Soup) (Mean $=2.35),(p=.001)$, higher in Scenario 1 (Soup) $($ Mean $=2.35)$ than that in Scenario 4 (Books) $($ Mean $=1.65),(p<.05)$, higher in Scenario $3($ Blocks $)($ Mean $=3.00)$ than that in Scenario $2($ Lunch $)($ Mean $=2.25),(p$ $<.01)$, and higher in Scenario $3($ Blocks) $($ Mean $=3.00)$ than that in Scenario 4 (Books) $($ Mean $=1.65),(p<.001)$.

I then conducted a one-way repeated measure ANOVA comparing U.S. mothers' autonomy support across the four scenarios. Since Sphericity was violated [W (5) $=20.39$, $p=.001]$, the Greenhouse-Geisser correction was used. The results revealed that U.S. mothers' levels of autonomy support also varies across the four scenarios, $F(2.21,41.97)$ $=10, p<.001, \eta^{2}=.35$. Bonferroni post-hoc tests comparing U.S. mothers' responses to the four scenarios revealed that the level of maternal autonomy support was higher in Scenario $3($ Blocks $)($ Mean $=3.00)$ than that in Scenario $1($ Soup $)($ Mean $=2.30),(p$ 
$<.01)$, higher in Scenario $2($ Lunch $)($ Mean $=2.60)$ than that in Scenario 4 (Books)

$($ Mean $=1.75),(p<.05)$, and higher in Scenario $3($ Blocks $)($ Mean $=3.00)$ than that in

Scenario $4($ Books $)($ Mean $=1.75),(p<.001)$.

\section{Research Question 5: Are Scores on the Perceived Parental Autonomy Support}

Scale Related to Autonomy Support and Restriction Levels Determined from

\section{Responses to the Four Scenarios?}

In order to answer Research Question 5, I conducted zero-order bivariate correlations between the average scores based on the final list of 10 P-PASS items (Mageau et al., 2015) and scores from the four scenarios, separately for U.S. and Chinese mothers. Results showed no statistically significant associations in either the U.S. $(\beta \mathrm{s}=$ $-.15-.36, p \mathrm{~s}=.13-.52)$ or Chinese sample $(\beta \mathrm{s}=.05-.38, p \mathrm{~s}=.10-.83)$.

\section{Discussion}

Self-determination theorists argue that autonomy is one of the fundamental human needs for well-being and achievement across the globe (Deci \& Ryan, 2002). Research on autonomy support has been conducted primarily with middle-class families and their school-aged or adolescent children (Grolnick et al., 2002; Lekes et al., 2010; Niemiec et al., 2006). This mixed-method study was conducted to provide descriptive evidence about how mothers in low-income families in the U.S. and in China support their young children's autonomy across caregiving domains, and to explore associations between scenario-based autonomy support and restriction levels and levels of autonomy support based on the Perceived Parental Autonomy Support Scale. The data were gathered from 20 U.S. mothers and 20 Chinese mothers.

\section{Qualitative Research Findings on Autonomy Support and Restriction}


My inductive coding resulted in nine codes, which to a large extent are similar to those that have been found previously (Grolnick et al., 2002; Grolnick \& Ryan, 1989; NICHD, 2008; Whipple et al., 2011) despite demographic differences between the current study sample and samples in previous research (predominantly White and relatively educated). According to SDT (Deci \& Ryan, 2002), respecting children's autonomy involves valuing their sense of volition and their voices, and willingness to let them experiment and make decisions within certain parameters. In contrast, if children's perspectives and thoughts are not valued, then their autonomy is restricted. In the current study, I found six autonomy support strategies that both U.S. and Chinese mothers said they would use across various caregiving domains. The code, mother let child experiment, is similar to how autonomy was operationalized in previous studies, such as letting children be in charge, mothers following children's pace (Whipple et al., 2011), and mothers' not denying children's right to certain desired activities (NICHD, 2008). The code, mother recognizes child's feelings, was also operationalized as autonomy supportive in Grolnick and Ryan's study (1989). The code, mother shows respect to child's views and agentic choices, is in line with how autonomy support was operationalized in multiple studies (Grolnick \& Ryan, 1989; NICHD, 2008; Whipple et al., 2011). The code, mother compromises, was in line with codes used in previous research to tap openness to negotiation and flexibility in rules (NICHD, 2008; Whipple et al., 2011). The codes mother explains and mother helps or teaches are also similar to those use in previous research (Grolnick \& Ryan, 1989; Grolnick et al., 2002).

I also found three autonomy restrictive behaviors that mothers said they would perform in response to the hypothetical challenges in a variety of caregiving situations. 
Judging by mothers' comments, autonomy restrictive behaviors seemed to involve firm control due to mothers' socialization goals. I did not hear mention of harsh punishment or even use of rewards The code mother imposes agenda would have been scored low on Grolnick and Ryan's (1989) nondirectiveness scale because it reflected imposition of mothers' agenda or allowing few agentic choices. Mothers said they would use two of the autonomy restrictive methods (not letting their children experiment because it is against the norms, but not telling child why, and not letting their children experiment because it is unhealthful, but not telling child why) along with some autonomy supportive strategies, such as providing rationales or offering assistance and guidance. As suggested by Cheung and Pomerantz (2011), many parents use both controlling and autonomy supportive strategies to help children to achieve socialization goals.

\section{Cross-Cultural Similarities in Responses to the Scenario-Based Interview and the Perceived Parental Autonomy Support Scale}

In the current study, the levels of autonomy support and restriction did not differ between the U.S. and Chinese mothers based on data from both the scenario-based interview and the quantitative measure (P-PASS; Mageau et al., 2015). This null finding is in contrast to cross-cultural differences found in previous research (Lekes et al., 2010; Rudy et al., 2007).

It is possible that my results differed from previous ones comparing U.S. and Chinese mothers because the target children's ages in the current study differed from target children's ages in previous research. Most research on perceived parental autonomy support has been conducted with school-age children, adolescents, or young adults (Lekes et al., 2010; Rudy et al., 2007). It is possible that the Chinese mothers, like 
the Mayan mothers studied by Mosier and Rogoff (2003) allowed children levels of autonomy comparable to those of U.S. mothers because the children were so young. At this age, fostering a close relationship may have been paramount in their minds. Greater control may be exercised when the children are older.

Moreover, the order in which the research protocol was introduced should be considered. Mothers responded to the P-PASS after they had had the chance to think about parenting during the scenario-based interview. When responding to the P-PASS, they may have been primed to think about the items differently than they might have if the study had only asked for questionnaire responses.

Further, Euro-centric measures might not be reliable or valid when used with nonNorth American cultural groups (Lekes et al., 2010). Lekes and colleagues (2010) asked 567 adolescents in Canada and the U.S. and 515 adolescents in China to respond to the Perception of Autonomy Support Scale (Robbins, 1994). Cronbach's alpha was only .60 for the Chinese sample $(n=515)$. Two items of this measurement, "My parents try to tell me how to run my life (reversed)"' and "My parents help me to choose my own direction," loaded negatively on the autonomy support construct. The researchers reasoned that it was due to translation problems and therefore decided to eliminate those two items. The final seven-item autonomy scale had a reliability coefficient of .79 for the Chinese sample. This example indicates that established measures might not work when used with samples other than North American middle-class families. It is also possible that the surprising loadings might to some extent reflect differences between individual autonomy and inclusive autonomy (Rudy et al., 2007). This calls for future research to 
understand how perceived autonomy might function differently across different cultures due to different processes of internalization of obligations and duties (Miller et al., 2011).

The similarities in autonomy support levels between U.S. and Chinese mothers might also be due to the fact that mothers in the current study were from low income backgrounds. Much of what we have known about parental autonomy support is based on samples from educated middle-class families in metropolitan areas (Bernier et al., 2010; Cheung \& Pomerantz, 2011; Grolnick \& Ryan, 1989; Keller et al., 2007; Lekes et al., 2010; Matte-Gagné \& Bernier, 2011; Wang et al., 2007). Additionally, mothers in the current study were recruited from childcare centers, where they are likely to be exposed to democratic ways of caregiving through their observations of and interactions with their children's teachers at the centers.

Furthermore, the U.S. mothers in the current study were from various ethnoracial backgrounds (Whites, Blacks and Latinas), reflecting the racial diversity of the U.S. lowincome population. Most cross-cultural research comparing autonomy support and restriction by North American and Chinese parenting has been conducted with European Americans representing U.S. values and practices (Cheung \& Pomerantz., 2011; Keller et al., 2007; Liu et al., 2005; Rudy et al., 2007; Wang et al., 2007).

Also, researchers have pointed out that parenting beliefs have changed across time in both the U.S. (Alwin, 1989; Wright \& Wright, 1976) and China (Zeng \& Greenfield, 2015). Most of the mothers in the current study were in their early 30's or younger. Most of the Chinese mothers in the current study were under the influence of the Open-Door policy to boost the economy by encouraging foreign imports and exports and attracting foreign investment (Quach \& Anderson, 2008; Wei, 1995). Many have access to the 
Internet. For these reasons, the Chinese mothers could be the beneficiaries of globalization. For the U.S. mothers, information is also much more widely distributed via the Internet currently than it was for previous generations even for low-income families according to a recent Pew Research Center report (Pew Research Center, 2018). To some extent, globalization might have contributed to the beliefs of mothers in the current samples that it is children's natural right to express their perspectives. Research on autonomy that was conducted even as recently as the early 2000s with infants or toddlers (Keller et al., 2007; Liu et al., 2005) or with adolescents (Lekes et al., 2010) might not reflect the younger generation of mothers' beliefs and strategies.

Another similarity between the two samples is that in both countries, there were no significant associations between autonomy support or restriction levels based on responses to the scenarios and those based on the Perceived Parental Autonomy Support Scale (P-PASS; Mageau et al., 2015). It seems that some items in P-PASS were worded too abstractly for some mothers to be able to give numeric responses, whereas the interviews facilitated responding because they asked mothers to think about concrete situations. It's notable that Chinese mothers had comments on some of the P-PASS items explaining that they were not able to provide numeric responses to certain items because "it depends" on the situation. As argued by Markus and Kitayama (1991), East Asians are more likely to think contextually than North Americans. One more possibility is that the authors of the P-PASS used it to measure youths or young adults' perceptions of their parents' autonomy support. For this study, I adapted the P-PASS items by changing from “My parents ..." (Mageau et al., 2015) to "I...". Future research should survey a larger 
group of participants to validate the use of the P-PASS for parents of very young children.

\section{Comparing Levels of Autonomy Support and Restrictions across Four Scenarios}

\section{Among mothers from both countries, levels of autonomy support or}

restriction differed across scenarios. The results revealed cross-scenario variations in

the responses of both U.S. and Chinese mothers. In this section, I will discuss two salient variations distinguishing the four scenarios.

For both the U.S. mothers and Chinese mothers, responses to Scenario 3 (Blocks) showed higher levels of autonomy support than responses to Scenarios 1 (Soup) and 4 (Books). It seems that most of the U.S. and Chinese mothers said they would let them experiment, in their response to Scenario 3 (Blocks), because it was "just playing." The U.S. and Chinese mothers were less autonomy supportive in situations concerning children's health and eating habits, e.g., Scenario 1 (Soup) or children's academic learning, e.g., Scenario 4 (Books). This interesting scenario-based difference stimulated me to reflect on how these scenarios were created when we were designing this study. Both my advisor and I have been trained in the field of human development and family science. When my advisor guided me to design these four scenarios, we grouped Scenario 3 (Blocks) and Scenario 4 (Books) in to one caregiving domain - the preacademic learning domain. We based our thinking on research showing that playing facilitates cognitive development, such as planning, problem solving, counting, selfregulation, and even social skills (Nicolopoulou, 1993; Tamis-LeMonda, Shannon, Cabrera, \& Lamb, 2004). In the current study, most of the U.S. and Chinese mothers said they would just let their children "do their own thing" when playing with blocks, 
allowing and even encouraging their children to figure things out through trial and error. Most of the U.S. and Chinese mothers' responses showed higher levels of autonomy support in regards to Scenario 3 (Blocks), when their children were building towers with blocks, than in regards to any other scenarios.

In contrast, most of the U.S. and Chinese mothers' responses showed lower levels of autonomy support (or higher levels of autonomy restriction) in Scenario 4 (Books) than in regards to any other scenarios. Most of mothers said they would not let their children experiment because it is against the norm. Most of the U.S. and Chinese mothers said they would correct their children right away if their children made the "oink, oink," sounds when they were reading about ducks because they wanted their children to know the correct information as they are learning. (Ducks "quack," and pigs "oink," according to the norms ${ }^{2}$.) Higher levels of autonomy restrictions (frequently coded as mother does not let child experiment because it's against the norm) might be explained by the age group of the target children in the current study. Most of the target children were about to transition to kindergarten. It is very likely that these mothers were concerned about their children's school readiness (Holloway et al., 1995). Wiley and colleagues (1998) suggested that, among the six focal children from two socioeconomically different neighborhoods, low-income mothers might have the belief that the right to express one's views needs to be earned by their children, which might be why low-income mothers were less likely to give in to children's incorrect assertions. Low-income mothers put more weight on the accuracy of children's comments than their middle-class counterparts

\footnotetext{
2 Though most of the mothers said they would make the "correct" sound and wanted to make sure their children knew the correct sounds of ducks, the American and Chinese ducks sounded different to me when the U.S. mothers made the sound ("quack, quack,") in their interviews compared to when Chinese mothers made the sounds ("ga, ga.")
} 
did. Would middle-class mothers in the U.S. and China be less strict on the accuracy of the information in the book-reading scenario? This would be a good question for future research to explore.

Play might not be perceived as part of pre-academic learning by the mothers that I interviewed, whereas reading might be perceived as more relevant to acquiring knowledge that is helpful for achieving pre-academic competence. Due to this belief, parents might prioritize correctness during language-related experiences (as during bookreading) over other socialization goals such as creativity and self-confidence. Evidence suggests that in Hong Kong, parental control of adolescents is greater in the academic domain than in nonacademic domains (e.g., peer relations) (Shek \& Lee, 2007). It should be noted that Joussemet and colleagues (2005) found that in fact, maternal autonomy support (measured when children were 5 years old) does predict academic achievement (measured when children were 8 years old). At the same time, it is important to note that their participant were White, and all children were from two-parent households. Parental autonomy support has been found to contribute to children's academic success in the U.S. and China (Cheung \& Pomerantz., 2011; Grolnick \& Ryan, 1989; NICHD, 2008).Some of the Chinese mothers in the current sample said that their children's childcare center emphasized playing whereas in other childcare centers in town (most likely privateowned and small-scale), preschool-aged children were studying math, reading, and English along with hours of homew ork at the end of every school day. These Chinese mothers were conflicted and concerned that their children would lag behind when entering kindergarten and especially first grade. They said they had to make sure their children were school-ready and could be competitive. I also heard from U.S. mothers 
who expressed conflicted feelings when choosing between promoting children's creativity and helping children get ready for school. It is very likely that the book reading scenario, compared to other hypothetical situations, is more tightly connected to preparing their children to be ready for school than any other scenarios in the minds of both the U.S. and Chinese mothers.

These scenario-specific variations echo domain theory (Smetana, 1988) that the importance of parental authority and parenting strategies might differ across different caregiving domains (Fung et al., 2017; Vansteenkiste, Soenens, Van Petegem, \& Duriez, 2014). The current study revealed that mothers said they would put different levels of emphases on autonomy support and restrictions across different caregiving contexts. Further attention is needed to consider variations in caregiving situations. It would also be interesting to hear preschoolers' perspectives on their mothers' rules across caregiving domains.

\section{Strengths, Limitations, and Future Directions}

The current study unveiled scenario-specific parenting decisions reflecting autonomy support and restriction of young children by low-income mothers in the U.S. and China. As part of the mixed methods design, I conducted the scenario-based interviews, which allowed my participants to share their thoughts, not only on what they would do and say, but also what made them decide what they said they would say and do. Their responses vis a vis the scenarios could be compared to their numeric responses to an established questionnaire on parental autonomy support (P-PASS; Mageau et al., 2015). Most of the existing research tapping autonomy support and restriction is based solely on questionnaires (e.g., Grolnick \& Ryan, 1989; Joussemet et al., 2005). By using 
scenario-based interviews, I was able to elicit mothers' decisions and rationales across four caregiving situations and helped them contextualize autonomy support strategies and autonomy restriction behaviors. I believe it is important for researchers to consider maternal autonomy supportive strategies and autonomy restrictive behaviors across different caregiving contexts. Further, there were benefits to my being available while mothers filled out the P-PASS and my offer to comment on each of the items, indicating if it was difficult to apply a simple numeric score to give to certain items. If parents hadn't had the opportunity to ask questions so that I could provide clarification, or didn't have the options to provide comments, the survey results might not have been valid reflections of participants' thoughts. Moreover, while many studies document higher autonomy restriction among low-income than middle-income mothers, my study contributes to knowledge about low-income mothers' reasoning in regards to autonomy support and restriction.

Despite the contributions of the current study, caveats are inevitable. First, only a small group of mothers were involved due to the time-intensive nature of qualitative interviewing and analysis. Therefore, the findings from the current study my not generalize to the broad population of low-income U.S. or Chinese mothers.

Second, my ethnoracial and cultural identity may have been an influential factor. My interviews with Chinese mothers were relatively longer, and Chinese mothers were very vocal and open about their thoughts and experiences. In contrast, the interviews with the U.S. mothers were relatively shorter and U.S. mothers were less likely to provide comments on the questionnaires. It is possible that parents in the U.S. are more private about their childrearing, but it is also possible that the U.S. mothers perceived me as an 
outsider. Chinese mothers might have felt especially comfortable because they knew that I was also born and raised in the same town where they were recruited. They might have been more likely to open up and share because they saw me as an insider and as an authority figure with expertise in child development and childrearing from a prestigious institution in the U.S. Future researchers should consider how the match or non-match of demographic characteristics between interviewers and participants affects study results.

Third, the group compositions of participants in the U.S. and China also differed. The U.S. mothers were from three ethnoracial groups and with different marital statuses. Three were primary caregivers, two of which were grandmothers and one a target child's older sister. In contrast, Chinese mothers were from a relatively homogenous background - all were married and all were biological mothers to the target child. It is very likely that these demographic characteristics played a role in similarities on levels of maternal autonomy support and restrictions between the U.S. and Chinese groups of mothers. Future researchers might consider what motherhood means in the U.S. and China, i.e., the identity of those who are raising our youngest generations in the U.S. and China, and how the ecology might influence the levels of maternal autonomy support and restrictions.

Fourth, the questionnaire included in this study was adapted from the P-PASS (Mageau et al., 2015), which was created to assess youths' perceived parental autonomy support and validated for participants of European decedent. I had to modify it by dropping two items in order to increase Cronbach's alphas for the U.S. and Chinese subsamples to acceptable levels ( $\alpha>.07$; George \& Mallery, 2003). Though the P-PASS has been used in some recently published studies (Costa et al., 2016; Mageau et al., 2015; 
Mageau et al., 2016; Won \& Yu, 2018), issues related to inter-item reliability, construct validity, and cross-cultural invariance should be fully considered in future cross-cultural research.

Fifth, though the current study was not designed to detect child gender differences regarding mothers' autonomy support and restriction decisions, child gender is an important factor to consider when examining parents' autonomy support and restriction levels (e.g., Tamis-LeMonda, Briggs, McClowry, \& Snow, 2009). In the current study, the four scenarios (Soup, Lunch, Blocks and Books) might not elicit parents' responses that are contingent upon child gender. It is very possible that parents might make slightly different decisions on whether and how to support or restrict children's autonomy in other types of caregiving situations. Future researchers should consider child gender when studying parents' autonomy supportive and restrictive behaviors across a wide range of caregiving domains.

Finally, it is important to assess young children's perceptions of autonomy support and restriction in their families. Ispa-Landa (2016) interviewed adolescents about their parents' expectations and rules. She also asked her participants to talk about their mothers' practices. Adolescents' or young adults' perceptions have also been repeatedly assessed in survey studies (e.g., Lekes et al., 2010; Rudy et al., 2007). SDT researchers should consider how pre-school-aged children perceive parental autonomy support and restriction (van der Kaap-Deeder, Vansteenkiste, Soenens, \& Mabbe, 2017).

\section{Implications and Conclusions}

The current study focused on U.S. and Chinese low-income mothers' responses to scenario-based interviews. My findings suggest that there is rising similarity in 
childrearing beliefs around the globe. The scenarios were useful for eliciting maternal autonomy supportive strategies or restrictive behaviors, and to show how they differed by caregiving context. The use of qualitative inquiry and a caregiving context-oriented method allowed participants to share what they would say and do, and the rationale behind their parenting decisions. This information will be valuable in informing future research and study-designs on cross-cultural parenting. Research on cross-cultural parenting should consider the influence of globalization and cultural diffusion and how it might impact parenting beliefs and behaviors in contemporary societies. Failing to consider diverse cultural, economic, and caregiving contexts may result in a limited view of parents' engagement in autonomy supportive or restricting behaviors. 


\section{References}

Alwin, D. F. (1989). Changes in qualities valued in children in the United States, 1964 to 1984. Social Science Research, 18, 195-236. doi:10.1016/0049-089X(89)90005-7

Alwin, D. F. (1990). Historical changes in parental orientations to children. Sociological Studies of Child Development, 3, 65-86.

Bayley, N., and Schaefer, E. S. (1960). Relationships between socioeconomic variables and the behavior of mothers toward young children. Journal of Genetic Psychology, 96, 61-77. doi: 10.1080/00221325.1960.10534275

Bernier, A., Carlson, S. M., \& Whipple, N. (2010). From external regulation to selfregulation: Early parenting precursors of young children's executive functioning. Child Development, 81, 326-339. doi: 10.1111/j.1467-8624.2009.01397.x

Bianchi, S. M. (2000). Maternal employment and time with children: Dramatic change or surprising continuity? Demography, 37, 401-414. doi:10.1353/dem.2000.0001

Blumer, H. (1986). Symbolic interactionism: Perspective and method. Englewood Cliffs, NJ: Prentice Hall.

Bornstein, M, H., \& Cheah, C. S. L. (2006). The place of "culture and parenting" in an ecological contextual perspective on developmental science. In K. H. Rubin \& O. B. Chung (Eds.), Parental beliefs, parenting, and child development in crosscultural perspective. London, UK: Psychology Press.

Bradley, R. H., Corwyn, R. F., McAdoo, H. P., \& Garcia Coll, C. (2000). The home environments of children in the United States, Part I: Variations by age, ethnicity, and poverty status. Child Development, 72, 1844-1867. doi: 10.1111/14678624.t01-1-00382 
Chen, X., Dong, Q., and Zhou, H. (1997). Authoritative and authoritarian parenting practices and social and school performance in Chinese children. International Journal of Behavioral Development, 21, 855-873. doi:

$10.1080 / 016502597384703$

Chen X., Rubin, K. H., \& Sun, Y. (1992). Social reputation and peer relationships in Chinese and Canadian children: A cross-cultural study. Child Development, 63, 1336-1343. Stable URL: http://www.jstor.org/stable/1131559

Cheung, C. S. S., \& Pomerantz, E. M. (2011). Parents' involvement in children's learning in the United States and China: Implications for children's academic and emotional adjustment. Child Development, 82, 932-950. doi:10.1111/j.14678624.2011.01582.x

Chirkov, V., Ryan, R. M., Kim, Y., \& Kaplan, U. (2003). Differentiating autonomy from individualism and independence: A self-determination theory perspective on internalization of cultural orientations and well-being. Journal of Personality and Social Psychology, 84, 97-110. doi:10.1037/00223514.84.1.97

Connell-Carrick K. (2006) Trends in popular parenting books and the need for parental critical thinking. Child Welfare 85, 819-836.

Corbin, J. \& Strauss, A. (2014). Basics of qualitative research: Techniques and procedures for developing grounded theory. Thousand Oaks, CA: Sage.

Costa, S., Cuzzocrea, F., Gugliandolo, M. C., \& Larcan, R. (2016). Associations between parental psychological control and autonomy support, and psychological outcomes in adolescents: The mediating role of need satisfaction and need 
frustration. Child Indicators Research, 9, 1059-1076. doi: 10.1007/s12187-015$9353-\mathrm{Z}$

Creswell, John, W. (2014). Research design: Qualitative, quantitative, and mixed method approaches (4th edition). London: Sage Publications.

Creswell, J. W., Klassen, A. C, Plano Clark, V. L., \& Smith, K. C., \& the Office of Behavioral and Social Sciences Research (2011). Best practices for mixed methods research in the health sciences. National Institutes of Health. Available at:http://obssr.od.nih.gov/mixed_methods_research.

Dai, Y., \& Dimond, M. F. (1998). Filial piety: A cross-cultural comparison and its implications for the well-being of older parents. Journal of Gerontological Nursing 24,13-8. doi: 10.3928/0098-9134-19980301-05

Deci, E. L., Eghrarl, H., Patrick, B. C., \& Leone, D. R. (1994). Facilitating internalization: The self-determination theory perspective. Journal of Personality, 62, 119-142. 10.1111/j.1467-6494.1994.tb00797.x

Deci, E. L., \& Ryan, R. M. (2000). The "what" and "why" of goal pursuits: Human needs and the self-determination of behavior. Psychological Inquiry, 11, 227-268. doi: 10.1207/S15327965PLI1104_01

Deci, E. L., \& Ryan, R. M. (Eds.) (2002). Handbook of self-determination research: Theoretical and applied issues. Rochester: University of Rochester Press.

Evans, G. W., \& Kim, P. (2013). Childhood poverty, chronic stress, self-regulation, and coping. Child Development Perspectives, 7, 43-48. doi: 10.1111/cdep.12013

Fung, H., Li, J., \& Lam, C. K. (2017). Multi-faceted discipline strategies of Chinese parenting. International Journal of Behavioral Development, 41, 472-481. doi: 


\section{$10.1177 / 0165025417690266$}

Gecas, V. (1979). The influence of social class on socialization. In W. R. Burr, R. Hill, F. I. Nye, and I. L. Reiss (Eds.), Contemporary theories about the family (pp. 365404). New York: Free Press.

George, D., \& Mallery, P. (2003). SPSS for Windows step by step: A simple guide and reference. 11.0 update (4th ed.). Boston: Allyn \& Bacon.

Gibbs, G. (2002) Qualitative data analysis: Explorations with NVivo. Buckingham: Open University Press.

Goodnow, J. J. (1985). Change and variation in ideas about childhood and parenting. In I. E. Sigel (Ed.), Parent belief systems (pp. 235-270). Hillsdale, NJ: Erlbaum.

Grolnick, W. S., Deci, E. L., \& Ryan, R. M. (1997), Internalization within the family. In J, E. Grusec \& L. Kuczynski (Eds.), Parenting and children's internalization of values: A handbook of contemporary theory (pp. 135-161). New York: Wiley.

Grolnick, W. S., Gurland, S. T., DeCourcey, W., \& Jacob, K. (2002). Antecedents and consequences of mothers' autonomy support: An experimental investigation. Developmental Psychology, 38, 143-155. doi: 10.1037//0012-1649.38.1.143

Grolnick, W. S., \& Ryan, R. M. (1989). Parent styles associated with children's selfregulation and competence in school. Journal of Educational Psychology, 81, 143-154. doi:10.1037//0022-0663.81.2.143

Hess, R. D. (1970). Social class and ethnic influences upon socialization. In P. H. Mussen (Ed.), Carmichael's manual of child psychology (3rd ed., Vol. 2, pp. 457-557). New York: Wiley. 
Hoff, E., Laursen, B., \& Tardiff, T. (2002). Socioeconomic status and parenting. In M. H. Bornstein (Ed.), Handbook of parenting (2nd ed., pp. 231-252). Mahwah, NJ: Erlbaum.

Hoff-Ginsberg, E. (1991). Mother-child conversation in different social classes and communicative settings. Child Development, 62, 782-796. doi: 10.1111/j.14678624.1991.tb01569.x

Holstein, J. A., \& Gubrium, J. F. (1995). The active interview. Thousand Oaks, CA: Sage. Holloway, S. D., Rambaud, M. F., Fuller, B., \& Eggers-Pierola, C. (1995). What is "appropriate practice" at home and in child care?: Low-income mothers' views on preparing their children for school. Early Childhood Research Quarterly, 10, 451473. doi: 10.1016/0885-2006(95)90016-0

Huludao. (n.d.). In Wikipedia. Retrieved February 27, 2018, from https://en.wikipedia.org/wiki/Huludao

Ispa, J. M., Su-Russell, C., Carlo, G., \& Palermo, F. (2017). The interplay of maternal sensitivity and toddler engagement of mother in predicting self-regulation. Developmental Psychology, 53, 425-435. doi: 10.1037/dev0000267

Ispa, J. M., Carlo, G., Palermo, F., Su-Russell, C., Harmeyer, E., \& Streit, C. (2015). Middle childhood feelings toward mothers: Predictions from maternal directiveness at the age of two and respect for autonomy currently. Social Development, 24, 541-560. doi: 10.1111/sode.12108

Ispa-Landa, S. (2016). Legitimizing family management: The role of adolescents' understandings of risk. Journal of Marriage and Family, 78, 516-530. doi: 10.1111/jomf.12280 
Iyengar, S. S., \& Lepper, M.R. (1999). Rethinking the value of choice: A cultural perspective on intrinsic motivation. Journal of Personality and Social Psychology, 76, 349-366. doi: 10.1037/0022-3514.76.3.349

Ji, Y. (2015). Between tradition and modernity: "Leftover" women in Shanghai. Journal of Marriage and Family, 77, 1057-1073. doi: 10.1111/jomf.12220

Joussemet, M., Koestner, R., Lekes, N., \& Landry, R. (2005). A longitudinal study of the relationship of maternal autonomy support to children's adjustment and achievement in school. Journal of Personality, 73, 1215-1236.

doi:10.1111/j.1467-6494.2005.00347.x

Keller, H., Abels, M., Borke J., Lamm, B., Lo, W., Su, Y., \& Wang, Y. (2007).

Socialization environments of Chinese and Euro-American middle-class babies: Parenting behaviors, verbal discourses and ethnotheories. International Journal of Behavioral Development, 31, 210-217. doi: 10.1177/0165025407074633

Lareau, A. (2011). Unequal childhoods: Class, race, and family life. Berkeley, CA: University of California Press

Lekes, N., Gingras, I., Philippe, F. L., Koestner, R., \& Fang, J. (2010). Parental autonomy-support, intrinsic life goals, and well-being among adolescents in China and North America. Journal of Youth and Adolescence, 39, 858-69. doi:10.1007/s10964-009-9451-7

Liu, J., Chen, X., Li, D., \& French, D. (2012). Shyness-sensitivity, aggression, and adjustment in urban Chinese adolescents at different historical times. Journal of Research on Adolescence, 22, 393-399. doi: 10.1111/j.1532-7795.2012.00790.x 
Liu, M., Chen, X., Rubin, K. H., Zheng, S., Cui, L., Li, D., . . Wang, L. (2005).

Autonomy- vs. connectedness-oriented parenting behaviors in Chinese and Canadian mothers. International Journal of Behavioral Development, 29(6), 489495. doi:10.1177/01650250500147063

Mageau, G. A., Bureau, J. S., Ranger, F., Allen, M-P., \& Soenens, B. (2016). The role of parental achievement goals in predicting autonomy-supportive and controlling parenting. Journal of Child and Family Studies, 25, 1702-1711. doi: $10.1007 / \mathrm{s} 10826-015-0341-1$

Mageau, G. A., Ranger, F., Joussemet, M., Koestner, R., Moreau, E., \& Forest, J. (2015). Validation of the perceived parental autonomy support scale (P-PASS). Canadian Journal of Behavioural Science, 47, 251-262. doi: 10.1037/a0039325

Manzi, C., Regalia, C., Pelucchi, S., \& Fincham, F. D. (2012). Documenting different domains of promotion of autonomy in families. Journal of Adolescence, 35, 289298. doi:10.1016/j.adolescence.2011.10.011

Markus, H. R., \& Kitayama, S. (1991). Culture and the self: Implications for cognition, emotion, and motivation. Psychological Review, 98, 224-253. doi:10.1037//0033295X.98.2.224

Matte-Gagné, C., \& Bernier, A. (2011). Prospective relations between maternal autonomy support and child executive functioning: Investigating the mediating role of child language ability. Journal of Experimental Child Psychology, 110, 611-625. doi: 10.1016/j.jecp.2011.06.006 
Miller, J. G., Das, R., \& Chakravarthy, S. (2011). Culture and the role of choice in agency. Journal of Personality and Social Psychology, 101, 46-61. doi: $10.1037 / \mathrm{a} 0023330$

Mosier, C. E., \& Rogoff, B. (2003). Privileged treatment of toddlers: Cultural aspects of individual choice and responsibility. Developmental Psychology, 39, 1047-1060. doi: 10.1037/0012-1649.39.6.1047-

National Institute of Child Health and Human Development Early Child Care Research Network (2004). Fathers' and mothers' parenting behavior and beliefs as predictors of children's social adjustment in the transition to school. Journal of Family Psychology, 18, 628-638. doi: 10.1037/0893-3200.18.4.628

National Institute of Child Health and Human Development Early Child Care Research Network (2008). Mothers' and fathers' support for child autonomy and early school achievement. Developmental Psychology, 44, 895-907. doi: 10.1037/00121649.44.4.895

Nicolopoulou, A. (1993). Play, cognitive development, and the social world: Piaget, Vygotsky, and beyond. Human Development, 36, 1-23. doi: 10.1159/000277285

Niemiec, C. R. Lynch, M. F., Vansteenkiste, M., Berstein, J., Deci, E. L., \& Ryan, R. M. (2006). The antecedents and consequences of autonomous self-regulation for college: A self-determination theory perspective on socialization. Journal of Adolescence, 29, 761-775. doi:10.1016/j.adolescence.2005.11.009

O’Brien M. (1996) Child-rearing difficulties reported by parents of infants and toddlers. Journal of Pediatric Psychology 21, 433-446. doi: 10.1093/jpepsy/21.3.433 
Oyserman, D., Coon, H. M., \& Kemmelmeier, M. (2002). Rethinking individualism and collectivism: Evaluation of theoretical assumptions and meta-analyses. Psychological Bulletin, 128, 3-72. doi: 10.1037//0033-2909.128.1.3

Park, H., \& Lau, A. S. (2016). Socioeconomic status and parenting priorities: Child independence and obedience around the world. Journal of Marriage and Family, 78, 43-59. doi: 10.1111/jomf.12247

Pew Research Center. (2018). Internet/Boardband fact sheet. Retrieved from http://www.pewinternet.org/fact-sheet/internet-broadband/

Porter, N., \& Ispa, J. M. (2013). Mothers' online message board questions about parenting infants and toddlers. Journal of Advanced Nursing, 69, 559-568. doi: 10.1111/j.1365-2648.2012.06030.x

Quach, A. S., \& Anderson, E. A. (2008). Implications of China's Open-Door Policy for families: A family impact analysis. Journal of Family Issues, 29, 1089-1103. doi: $10.1177 / 0192513 X 08316268$

Robbins, R. J. (1994). An assessment of perceptions of parental autonomy support and control: Child and parent correlates. Unpublished Doctoral Dissertation, University of Rochester.

Rubin, L. (1994). Families on the fault line. New York: Harper.

Rudy, D., Sheldon, K. M., Awong, T., \& Tan, H. H. (2007). Autonomy, culture, and well-being: The benefits of inclusive autonomy. Journal of Research in Personality, 41, 983-1007. doi:10.1016/j.jrp.2006.11.004

Russell, S. T., Crockett, L. J, \& Chao, R. K. (2010). Conclusions: The role of Asian American culture in parenting and parent-adolescent relationships. In S.T. 
Russell, L. J. Crockett, \& K. Chao (eds.), Advancing responsible adolescent development: Asian American parenting and parent-adolescent relationships, (pp. 117-128). Springer: New York. doi:10.1007/978-1-4419-5728-3_7

Ryan, R. M., \& Deci, E. L. (2002). On assimilating identities to the self: a selfdetermination theory perspective on internalization and integrity within cultures. In M. R. Leary, \& J. P. Tangney (Eds.), Handbook of self and identity (pp. 255273). New York: Guilford.

Seccombe, W. (1995). Weathering the storm: Working-class families from the industrial revolution to the fertility decline. New York: Verso.

Shek, D. T. L., \& Lee, T. Y. (2007). Parental behavioral control in academic and nonacademic domains: A three-year longitudinal study in the Chinese culture. International Journal of Adolescent Medicine and Health, 19, 529-538. doi: 10.1515/IJAMH.2007.19.4.529

Sheldon, K. M., Kasser, T., Houser-Marko, L., Jones, T., \& Turban, D. (2005). Doing one's duty: Chronological age, felt autonomy, and subjective well-being. European Journal of Personality, 19, 97-115. doi:10.1002/per.535

Smetana, J. G. (1988). Adolescents' and parents' conceptions of parental authority. Child Development, 59, 321-335. Stable URL: http://www.jstor.org/stable/1130313

Tamis-LeMonda, C. S., Briggs, R. D., McClowry, S. G., \& Snow, D. L. (2009). Maternal control and sensitivity, child gender, and maternal education in relation to children's behavioral outcomes in African American families. Journal of Applied Developmental Psychology, 30, 321-331. doi:10.1016/j.appdev.2008.12.018 
Tamis-LeMonda, C., Shannon, J. D., Cabrera, N. J., \& Lamb, M. E. (2004). Fathers and mothers at play with their 2- and 3-year-olds: Contributions to language and cognitive development. Child Development, 75, 1806-1820. doi: 10.1111/j.14678624.2004.00818.x

U.S. Census Bureau (2017). QuickFacts: Columbia city, Missouri. Retrieved from https://www.census.gov/quickfacts/fact/table/columbiacitymissouri/PST040217 van der Kaap-Deeder, J., Vansteenkiste, M., Soenens, B., \& Mabbe, E. (2017). Children’s daily well-being: The role of mothers', teachers', and siblings' autonomy support and psychological control. Developmental Psychology, 53, 237-251. doi:10.1037/dev0000218

Vansteenkiste, M., Soenens, B., Van Petegem, S., \& Duriez, B. (2014). Longitudinal associations between adolescent perceived degree and style of parental prohibition and internalization and defiance. Developmental Psychology, 50, 229236. doi: $10.1037 / \mathrm{a} 0032972$

Vansteenkiste, M., Zhou, M., Lens, W., \& Soenens, B. (2005). Experiences of autonomy and control among Chinese learners: Vitalizing or immobilizing? Journal of Educational Psychology, 97, 468-483. doi:10.1037/0022-0663.97.3.468

Vygotsky, L. S. (1978). Mind in society: The development of higher mental process. Cambridge, MA: Harvard University Press

Wang, Q., Chan, H-W., \& Lin, L. (2012). Antecedents of Chinese parents' autonomy support and psychological control: The interplay between parents' selfdevelopment socialization goals and adolescents' school performance. Journal of Youth Adolescence, 41, 1442-1454. doi: 10.1007/s10964-012-9760-0 
Wang, Q., Pomerantz, E. M., \& Chen, H. (2007). The roles of parents' control in early adolescents' psychological functioning: A longitudinal investigation in the United States and China. Child Development, 78, 1592-1610. Stable URL: http://www.jstor.org/stable/4620723

Wei, S. J. (1995). Open-Door Policy and China's rapid growth: Evidence from city-level data. NBER Working Paper No. 4602, National Bureau of Economic Research.

Whipple, N., Bernier, A., \& Mageau, G. A. (2011). Broadening the study of infant security of attachment: Maternal autonomy-support in the context of infant exploration. Social Development, 20, 17-32. doi: 10.1111/j.14679507.2010.00574.x

Wiley, A. R., Rose, A. J., Burger, L. K., \& Miller, P. J. (1998). Constructing autonomous selves through narrative practices: A comparative study of working-class and middle-class families. Child Development, 69, 833-847. doi: 10.2307/1132207

Won, S., \& Yu, S. L. (2018). Relations of perceived parental autonomy support and control with adolescents' academic time management and procrastination. Learning and Individual Differences, 61, 205-215. doi: 10.1016/j.lindif.2017.12.001

Wright, J. D., and Wright, S. R. (1976). Social class and parental values for children: A partial replication and extension of the Kohn thesis. American Sociological Review 41, 527-537. Stable URL: http://www.jstor.org/stable/2094258 
Yeh, K. H., \& Yang, Y. J. (2006). Construct validation of individuating and relating autonomy orientations in culturally Chinese adolescents. Asian Journal of Social Psychology, 9(2), 148-160. doi:10.1111/j.1467-839X.2006.00192.x

Yoshikawa, H., Weisner, T. S., Kalil, A., \& Way, N. (2008). Mixing qualitative and quantitative research in developmental science: Uses and methodological choices. Developmental Psychology, 44, 344-354. doi: 10.1037/0012-1649.44.2.344

Zeng, R., \& Greenfield, P. M. (2015). Cultural evolution over the last 40 years in China: Using the google ngram viewer to study implications of social and political change for cultural values. International Journal of Psychology, 50, 47-55. doi: 10.1002/ijop.12125 


\section{Tables}

Table 1

Participating Families' Demographic Characteristics $(N=40)$

\begin{tabular}{|c|c|c|}
\hline & U.S. & China \\
\hline \multicolumn{3}{|l|}{ Child Gender } \\
\hline Girls & $n=9(45 \%)$ & $n=13(65 \%)$ \\
\hline Boys & $n=11(55 \%)$ & $n=7(35 \%)$ \\
\hline Child Age (M, SD, range) & $\begin{array}{l}\text { Mean }=3.90, S D=.79, \\
\text { range }=3-6\end{array}$ & $\begin{array}{l}\text { Mean }=4.66, S D=.71, \\
\text { range }=4-7\end{array}$ \\
\hline Mother Figure Age & $\begin{array}{l}\text { Mean }=31.75, S D=9.19, \\
\text { range }=20-56\end{array}$ & $\begin{array}{l}\text { Mean }=33.60, S D=3.93, \\
\text { range }=28-46\end{array}$ \\
\hline \multicolumn{3}{|l|}{ Relationships with Child } \\
\hline Biological Mother & $n=17(85 \%)$ & $n=20(100 \%)$ \\
\hline Biological Grandmother & $n=2(10 \%)$ & $N / A$ \\
\hline Biological Sister & $n=1(5 \%)$ & $N / A$ \\
\hline \multicolumn{3}{|l|}{ Marital Status } \\
\hline Married & $n=7(35 \%)$ & $n=20(100 \%)$ \\
\hline Cohabiting & $n=5(25 \%)$ & $N / A$ \\
\hline Divorced & $n=1(5 \%)$ & $N / A$ \\
\hline Single & $n=7(35 \%)$ & $N / A$ \\
\hline \multicolumn{3}{|l|}{ Education } \\
\hline Less than High School & $n=3(15 \%)$ & $n=3(15 \%)$ \\
\hline GED & $n=5(25 \%)$ & $n=3(15 \%)$ \\
\hline
\end{tabular}




\begin{tabular}{|c|l|l|}
\hline Some College & $n=8(40 \%)$ & $n=5(25 \%)$ \\
\hline Bachelors’ Degrees & $n=4(20 \%)$ & $n=9(45 \%)$ \\
\hline Family Income & $n=5(25 \%)$ & $n=6(30 \%)$ \\
\hline Refused to answer & $\$ 20878,57(\$ 11232.38)$ & $¥ 85666.67(¥ 30930.03)$ \\
\hline M, SD, range & $\$ 800-\$ 40,000$ & $¥ 20,000-¥ 145,000$ \\
\hline Race (U.S.) & $n=8(40 \%)$ & \\
\hline White & $n=9(45 \%)$ & \\
\hline Black & $n=3(15 \%)$ & \\
\hline Latino & & \\
\hline
\end{tabular}


Table 2

Codes, Categories, Definitions, and Quotes $(N=40)$

\begin{tabular}{|c|c|c|c|c|c|c|c|c|c|}
\hline & & \multicolumn{8}{|c|}{ Frequencies } \\
\hline & & \multicolumn{4}{|c|}{ Domain: Mealtime } & \multicolumn{4}{|c|}{ Domain: Learning } \\
\hline & & \multicolumn{2}{|c|}{$\begin{array}{l}\text { Scenario } 1 \\
\text { (Soup) }\end{array}$} & \multicolumn{2}{|c|}{$\begin{array}{l}\text { Scenario } 2 \\
\text { (Lunch) }\end{array}$} & \multicolumn{2}{|c|}{$\begin{array}{l}\text { Scenario } 3 \\
\text { (Blocks) }\end{array}$} & \multicolumn{2}{|c|}{$\begin{array}{l}\text { Scenario } 4 \\
\text { (Books) }\end{array}$} \\
\hline Categories & Codes & U.S. & $\mathbf{C H}$ & U.S. & $\mathbf{C H}$ & U.S. & $\mathbf{C H}$ & U.S. & $\mathbf{C H}$ \\
\hline \multirow[t]{6}{*}{$\begin{array}{l}\text { Autonomy } \\
\text { Support }\end{array}$} & $\begin{array}{l}\text { Let } \mathrm{C} \\
\text { experiment }\end{array}$ & $\begin{array}{l}7 \\
(35 \%)\end{array}$ & $\begin{array}{l}4 \\
(20 \%)\end{array}$ & $\mathbf{0}$ & $\mathbf{0}$ & $\begin{array}{l}18 \\
(90 \%)\end{array}$ & $\begin{array}{l}16 \\
(80 \%)\end{array}$ & $\begin{array}{l}5 \\
(25 \%)\end{array}$ & $\begin{array}{l}4 \\
(20 \%)\end{array}$ \\
\hline & $\begin{array}{l}\text { M } \\
\text { recognizes } \\
\text { C's feelings }\end{array}$ & $\begin{array}{l}1 \\
(5 \%)\end{array}$ & $\begin{array}{l} \\
(10 \%)\end{array}$ & $\begin{array}{l}1 \\
(5 \%)\end{array}$ & $\begin{array}{l}2 \\
(10 \%)\end{array}$ & $\begin{array}{l}4 \\
(20 \%)\end{array}$ & $\begin{array}{l}5 \\
(25 \%)\end{array}$ & $\begin{array}{l}1 \\
(5 \%)\end{array}$ & $\begin{array}{l} \\
(10 \%)\end{array}$ \\
\hline & $\begin{array}{l}\text { M respects } \\
\text { C's views }\end{array}$ & $\begin{array}{l}1 \\
(5 \%)\end{array}$ & $\begin{array}{l}1 \\
(5 \%)\end{array}$ & $\begin{array}{l}15 \\
(75 \%)\end{array}$ & $\begin{array}{l}6 \\
(30 \%)\end{array}$ & $\begin{array}{l}1 \\
(5 \%)\end{array}$ & $\mathbf{0}$ & $\begin{array}{l}4 \\
(20 \%)\end{array}$ & $\begin{array}{l}4 \\
(20 \%)\end{array}$ \\
\hline & $\begin{array}{l}\text { M } \\
\text { compromise } \\
\mathrm{S}\end{array}$ & $\begin{array}{l}10 \\
(50 \%)\end{array}$ & $\begin{array}{l}12 \\
(60 \%)\end{array}$ & $\begin{array}{l}5 \\
(25 \%)\end{array}$ & $\begin{array}{l}3 \\
(15 \%)\end{array}$ & $\mathbf{0}$ & $\mathbf{0}$ & $\mathbf{0}$ & $\mathbf{0}$ \\
\hline & M explains & $\begin{array}{l}1 \\
(5 \%)\end{array}$ & $\begin{array}{l}10 \\
(50 \%)\end{array}$ & $\begin{array}{l}4 \\
(20 \%)\end{array}$ & $\begin{array}{l}8 \\
(40 \%)\end{array}$ & $\mathbf{0}$ & $\mathbf{0}$ & $\mathbf{0}$ & $\mathbf{0}$ \\
\hline & $\begin{array}{l}\text { M teaches or } \\
\text { helps }\end{array}$ & $\mathbf{0}$ & $\mathbf{0}$ & $\mathbf{0}$ & $\mathbf{0}$ & $\begin{array}{l}4 \\
(20 \%)\end{array}$ & $\begin{array}{l}7 \\
(35 \%)\end{array}$ & $\begin{array}{l}6 \\
(30 \%)\end{array}$ & $\begin{array}{l}5 \\
(25 \%)\end{array}$ \\
\hline \multirow[t]{3}{*}{$\begin{array}{l}\text { Autonomy } \\
\text { Restriction }\end{array}$} & $\begin{array}{l}\text { M doesn't } \\
\text { let } C \\
\text { experiment- } \\
\text { against norm }\end{array}$ & $\begin{array}{l}2 \\
(10 \%)\end{array}$ & $\begin{array}{l}5 \\
(25 \%)\end{array}$ & $\mathbf{0}$ & $\mathbf{0}$ & $\mathbf{0}$ & $\mathbf{0}$ & $\begin{array}{l}14 \\
(70 \%)\end{array}$ & $\begin{array}{l}15 \\
(75 \%)\end{array}$ \\
\hline & $\begin{array}{l}\text { M doesn't } \\
\text { let } \mathrm{C} \\
\text { experiment- } \\
\text { not good for } \\
\text { health }\end{array}$ & $\begin{array}{l}7 \\
(35 \%)\end{array}$ & $\begin{array}{l}6 \\
(30 \%)\end{array}$ & $\begin{array}{l}1 \\
(5 \%)\end{array}$ & $\begin{array}{l}2 \\
(10 \%)\end{array}$ & $\mathbf{0}$ & $\mathbf{0}$ & $\mathbf{0}$ & $\mathbf{0}$ \\
\hline & $\begin{array}{l}\text { M imposes } \\
\text { agenda }\end{array}$ & $\mathbf{0}$ & $\mathbf{0}$ & $\begin{array}{l}4 \\
(20 \%)\end{array}$ & $\begin{array}{l}9 \\
(45 \%)\end{array}$ & $\mathbf{0}$ & $\mathbf{0}$ & $\mathbf{0}$ & $\mathbf{0}$ \\
\hline
\end{tabular}


Table 3

Autonomy Support Scale by Item, Mean, SD, Range, and the Number Items of "It

Depends" in U.S. and China $(N=40)$

\begin{tabular}{|c|c|c|c|c|}
\hline & \multicolumn{2}{|c|}{ The U.S. } & \multicolumn{2}{|c|}{ China } \\
\hline Items & $\begin{array}{l}\text { Mean (SD) } \\
\text { Range }\end{array}$ & $\begin{array}{l}\text { \# of "it } \\
\text { depends" }\end{array}$ & $\begin{array}{l}\text { Mean (SD) } \\
\text { Range }\end{array}$ & $\begin{array}{l}\text { \# of "it } \\
\text { depends" }\end{array}$ \\
\hline $\begin{array}{l}\text { 1. I give my child opportunities to } \\
\text { make his/her own decisions about } \\
\text { what s/he is doing. }\end{array}$ & $\begin{array}{l}6.10(1.25) \\
2-7\end{array}$ & 0 & $\begin{array}{l}6.44(.89) \\
4-7\end{array}$ & 2 \\
\hline $\begin{array}{l}\text { 2. When I ask my child to do } \\
\text { something, I explain why I want } \\
\text { him/her to do it. }\end{array}$ & $\begin{array}{l}5.65(1.31) \\
2-7\end{array}$ & 0 & $\begin{array}{l}6.40(1.05) \\
4-7\end{array}$ & 1 \\
\hline $\begin{array}{l}\text { 3. My child's point of view is very } \\
\text { important to me when I make } \\
\text { important decisions concerning } \\
\text { him/her. }\end{array}$ & $\begin{array}{l}5.95(1.32) \\
2-7\end{array}$ & 0 & $\begin{array}{l}6.17(1.65) \\
1-7\end{array}$ & 3 \\
\hline $\begin{array}{l}\text { 4. I encourage my child to be } \\
\text { him/herself. }\end{array}$ & $\begin{array}{l}6.75(.44) \\
6-7\end{array}$ & 0 & $\begin{array}{l}6.50(.95) \\
4-7\end{array}$ & 0 \\
\hline $\begin{array}{l}\text { 5. Within certain limits, I allow my } \\
\text { child the freedom to choose his/her } \\
\text { own activities. }\end{array}$ & $\begin{array}{l}6.40(.68) \\
5-7\end{array}$ & 0 & $\begin{array}{l}6.78(.62) \\
5-7\end{array}$ & 0 \\
\hline
\end{tabular}




\begin{tabular}{|c|c|c|c|c|}
\hline $\begin{array}{l}\text { 6. When my child is not allowed to } \\
\text { do something, s/he usually knows } \\
\text { why. }\end{array}$ & $\begin{array}{l}5.55(1.28) \\
3-7\end{array}$ & 0 & $\begin{array}{l}6.33(1.19) \\
2-7\end{array}$ & 2 \\
\hline $\begin{array}{l}\text { 7. I am able to put myself in my } \\
\text { child's shoes and understand his/her } \\
\text { feelings. }\end{array}$ & $\begin{array}{l}5.80(1.24) \\
3-7\end{array}$ & 0 & $\begin{array}{l}5.95(1.19) \\
4-7\end{array}$ & 0 \\
\hline $\begin{array}{l}\text { 8. I hope that my child would make } \\
\text { choices that correspond to his/her } \\
\text { interests and preferences regardless } \\
\text { of what mine are. }\end{array}$ & $\begin{array}{l}6.30(1.03) \\
3-7\end{array}$ & 0 & $\begin{array}{l}6.05(1.00) \\
4-7\end{array}$ & 0 \\
\hline $\begin{array}{l}\text { 9. I am open to my child's thoughts } \\
\text { and feelings even when they are } \\
\text { different from mine. }\end{array}$ & $\begin{array}{l}6.75(.55) \\
5-7\end{array}$ & 0 & $\begin{array}{l}6.25(1.00) \\
4-7\end{array}$ & 2 \\
\hline $\begin{array}{l}\text { 10. I make sure that my child } \\
\text { understand why I forbid certain } \\
\text { things. }\end{array}$ & $\begin{array}{l}6.25(1.33) \\
2-7\end{array}$ & 0 & $\begin{array}{l}6.35(1.04) \\
4-7\end{array}$ & 0 \\
\hline $\begin{array}{l}\text { 11. When my child asks why s/he has } \\
\text { to do, or not do, something, I give } \\
\text { him/her good reasons. }\end{array}$ & $\begin{array}{l}6.30(1.13) \\
3-7\end{array}$ & 0 & $\begin{array}{l}6.30(1.49) \\
1-7\end{array}$ & 0 \\
\hline $\begin{array}{l}\text { 12. I listen to my child's opinion and } \\
\text { point of view when s/he disagrees } \\
\text { with me. }\end{array}$ & $\begin{array}{l}6.05(1.15) \\
3-7\end{array}$ & 0 & $\begin{array}{l}5.19(1.64) \\
1-7\end{array}$ & 4 \\
\hline
\end{tabular}

Note. Items 7 and 8 were eliminated in the current study. 


\section{Figures}

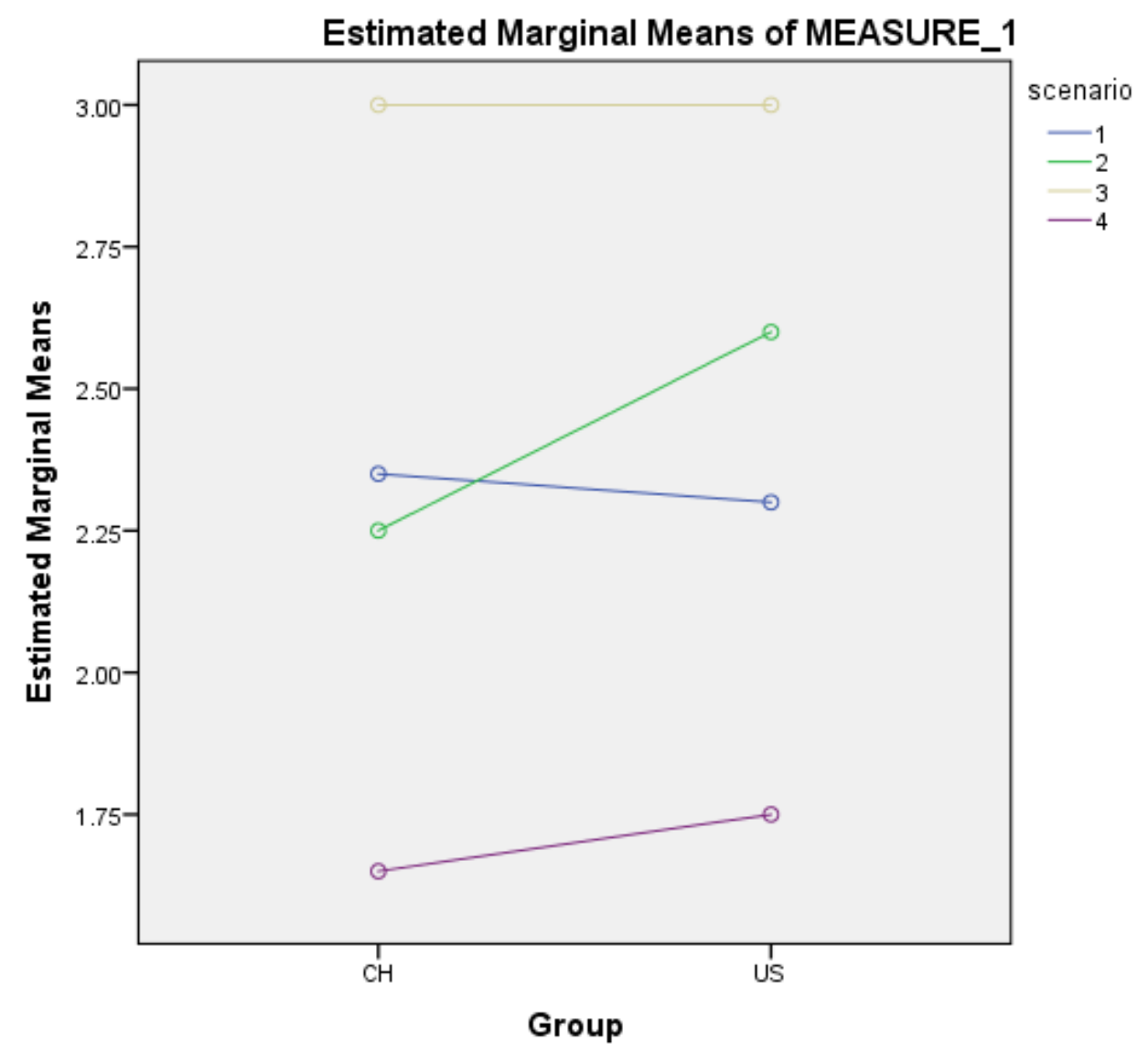

Figure 1. Repeated Measure ANOVA comparing autonomy supportive levels of four scenarios across the U.S. and Chinese cultures.

Note. Scenario 1 (Soup), Scenario 2 (Lunch), Scenario 3 (Blocks), and Scenario 4 (Books). 


\section{Appendices}

\section{Appendix A - Screening Survey}

1. Is there a child in your family who is between the age of 4 to 6 years old?
a. Yes
b. No

2. What is your child's gender?
a. Girl
b. Boy

3. What is your relation to this child?

4. Are you currently living with this child?
a. Yes
b. No 
Appendix B - Perceived Parental Autonomy Support Scale (P-PASS; Mageau et al., 2015)

To what extent do you agree on the following statements regarding your own behaviors?

\begin{tabular}{|c|c|c|c|c|c|c|}
\hline 1 & 2 & 3 & 4 & 5 & 6 & 7 \\
\hline $\begin{array}{c}\text { Do not } \\
\text { agree at } \\
\text { all }\end{array}$ & $\begin{array}{c}\text { Hardly } \\
\text { agree }\end{array}$ & $\begin{array}{c}\text { Slightly } \\
\text { agree }\end{array}$ & $\begin{array}{c}\text { Somewhat } \\
\text { agree }\end{array}$ & Agree & $\begin{array}{c}\text { Strongly } \\
\text { agree }\end{array}$ & $\begin{array}{c}\text { Very } \\
\text { strongly } \\
\text { agree }\end{array}$ \\
\hline
\end{tabular}

1. I give my child opportunities to make his/her own decisions about what $\mathrm{s} / \mathrm{he}$ is doing. (1)

2. When I ask my child to do something, I explain why I want him/her to do it. (2)

3. My child's point of view is very important to me when I make important decisions concerning him/her. (4)

4. I encourage my child to be him/herself. (7)

5. Within certain limits, I allow my child the freedom to choose his/her own activities. (8)

6. When my child is not allowed to do something, s/he usually knows why. (9)

7. I am able to put myself in my child's shoes and understand his/her feelings. (13)

8. I hope that my child would make choices that correspond to his/her interests and preferences regardless of what mine are. (14)

9. I am open to my child's thoughts and feelings even when they are different from mine. (16)

10. I make sure that my child understand why I forbid certain things. (19)

11. When my child asks why s/he has to do, or not do, something, I give him/her good reasons. (23)

12. I listen to my child's opinion and point of view when s/he disagrees with me. (24) 


\section{Appendix C - Demographic Information}

1. How old are you?

a. years old

2. How many years of education do you have?

a. years

3. What is the highest degree or level of school you have completed? If currently enrolled, mark the previous grade or highest degree received.
a. No school completed
b. 8th grade
c. $9^{\text {th }}, 10^{\text {th }}$, or $11^{\text {th }}$ grade
d. $12^{\text {th }}$ grade, no diploma
e. High school graduate (GED)
f. Some college (1-2 years)
g. Associate degree (AA or AS)
h. Bachelor's degree (BA, or BS)
i. Master's degree (MA, MS, Med, MSW, or MBA)
j. Others:

4. What is your relationship status?
a. Single
b. Cohabitating
c. Married
d. Separated
e. Divorced 


\section{f. Widowed}

5. What is the total number of people in your household?

a.

b.

6. What is your employment status?
a. Employed for wages
b. Out of work and looking for work
c. Out of work but not currently looking for work
d. A homemaker
e. Unable to work
f. Retired

7. What is your total household income?
c. Less than $\$ 10,000$
d. $\$ 10,000$ to $\$ 19,999$
e. $\$ 20,000$ to $\$ 29,999$
f. $\$ 30,000$ to $\$ 39,999$
g. $\$ 40,000$ to $\$ 49,999$
h. $\$ 50,000$ to $\$ 59,999$
i. $\$ 60,000$ to $\$ 69,999$
j. $\$ 70,000$ to $\$ 79,999$
k. $\$ 80,000$ to $\$ 89,999$
1. $\$ 90,000$ to $\$ 99,999$ 


\section{VITA}

Chang Su-Russell was born in Huludao, Liao Ning province, China on May 15, 1986. Chang grew up in Huludao, Liao Ning province and graduated from No. 1 High School in 2005. She attended Minzu University of China and received her B.A. in English Literature in 2009. She then come to the U.S. to work towards her M.A. in Child Development in the department of Human Development and Family Science at Michigan State University in 2011. Chang attended her doctoral program in the department of Human Development and Family Science at the University of Missouri in 2011, when and where she met her soul mate and best friend Luke. T. Russell. They got married in June 2013. Chang completed her doctoral work in Human Development and Family Science and pursued her Ph.D. in Human Environmental Science at the University of Missouri in 2018. 